University of San Diego

Digital USD

Fall 9-26-2018

\title{
Habitat Preferences of Blue Marlin (Makaira nigricans) and Black Marlin (Istiompax indica) in the Eastern Pacific Ocean
}

\author{
Nima Farchadi \\ University of San Diego \\ Michael G. Hinton \\ Inter-American Tropical Tuna Commission \\ Andrew R. Thompson \\ Southwest Fisheries Science Center \\ Zhi-Yong Yin \\ University of San Diego
}

Follow this and additional works at: https://digital.sandiego.edu/theses

Part of the Applied Statistics Commons, Oceanography Commons, Population Biology Commons, Statistical Models Commons, and the Terrestrial and Aquatic Ecology Commons

\section{Digital USD Citation}

Farchadi, Nima; Hinton, Michael G.; Thompson, Andrew R.; and Yin, Zhi-Yong, "Habitat Preferences of Blue Marlin (Makaira nigricans) and Black Marlin (Istiompax indica) in the Eastern Pacific Ocean" (2018).

Theses. 32.

https://digital.sandiego.edu/theses/32

This Thesis: Open Access is brought to you for free and open access by the Theses and Dissertations at Digital USD. It has been accepted for inclusion in Theses by an authorized administrator of Digital USD. For more information, please contact digital@sandiego.edu. 


\title{
UNIVERSITY OF SAN DIEGO
}

\author{
San Diego
}

\section{Habitat Preferences of Blue Marlin (Makaira nigricans) and Black Marlin} (Istiompax indica) in the Eastern Pacific Ocean

A thesis submitted in partial satisfaction of the requirements for the degree of

\section{Master of Science in Marine Science}

by

Nima Jason Farchadi

Thesis Committee

Michael G. Hinton, Ph.D., Chair

Andrew R. Thompson, Ph.D.

Zhi-Yong Yin, Ph.D. 
The thesis of Nima Jason Farchadi is approved by:

Michael G. Hinton, Ph.D., Chair Inter-American Tropical Tuna Commission

Andrew R. Thompson, Ph.D.

Southwest Fisheries Science Center

Zhi-Yong Yin, Ph.D.

University of San Diego

University of San Diego

San Diego

2018

ii 
(C) 2018 Nima Jason Farchadi 


\section{ACKNOWLEDGMENTS}

First and foremost, I would like to acknowledge all my committee members. Thank you to my committee chair, Dr. Michael G. Hinton for without his mentorship and advising I would not have gotten to this stage. His scientific insight, perception, and compassion are some of the many aspects of his mentorship that helped with the completion of this thesis. Michael is the reason I made it through USD, and him constantly challenging and supporting me has helped me become the scientist I am today

I would also like to thank Dr. Andrew R. Thompson. Without Andrew this project probably would have gone in a totally different direction. Andrew's expertise and knowledge in studying species spatiotemporal distribution helped immensely with this project. Additionally, his enthusiasm and encouragement helped me feel like I belong in the scientific world. He has been a great mentor and role model, and I hope one day I get good enough to surf with you.

This thesis also could not have been possible if it wasn't for Dr. Zhi-Yong "John" Yin. John always had an open door and has been enormously helpful in the spatial analysis of this data. John was always there to help me with problems I had with GIS and finding environmental data which is a whole another task on its own.

Next, I would like to thank the Inter-American Tropical Tuna Commission for providing me with the catch data. Without this, there would have been no project. Additionally, I would like to thank all of the EOS faculty. You all have been extremely helpful and taught me more about marine science and how to be a 
better scientist than I could have ever expected. To all of the graduate students, you are a fantastic group of people and for the past three years you have been my family here in San Diego. I will always cherish our memories in the graduate lounge, walks around campus, trivia at ballast point, etc.

I would like to acknowledge my family and friends for their love and support throughout this journey. I can't thank Rachel Whelan enough for being there by my side my time here at USD. Rachel was always there encouraging me and more importantly always willing to read and edits my papers. Lastly, even though they had no clue what I was doing (or why), my parents and brother have supported me every step of the way. As a young boy they have always taught me to reach for the stars and I am so fortunate to have these people in my life. 


\section{TABLE OF CONTENTS}

LIST OF TABLES .............................................................

LIST OF FIGURES .............................................................

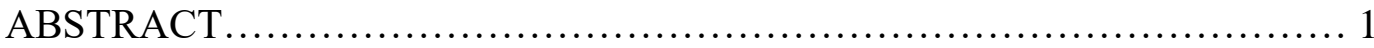

CHAPTER 1: Introduction

1.1 Taxonomy and morphology ......................................... 3

1.2 Development, reproduction, and sexual maturity........................5

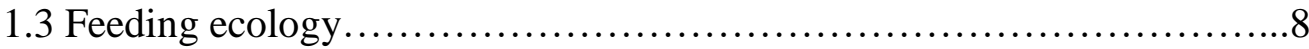

1.4 Geographic distribution and habitat...................................9

1.5 Oceanography of eastern Pacific Ocean............................... 10

1.5.1 Surface currents and water masses...............................10

1.5.2 Productivity and seasonal variations............................12

1.5.3 ENSO_.............................................................

1.6 Eastern Pacific Ocean tuna purse-seine fishery..........................17

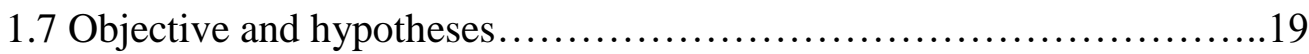

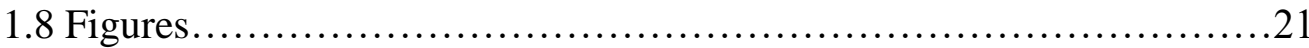

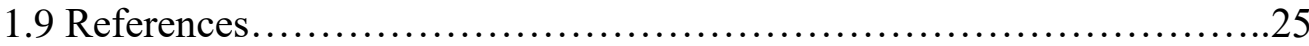

CHAPTER 2: Habitat Preferences of Blue Marlin (Makaira nigricans) and Black Marlin (Istiompax indica) in the Eastern Pacific Ocean

2.1 Introduction........................................................... 31

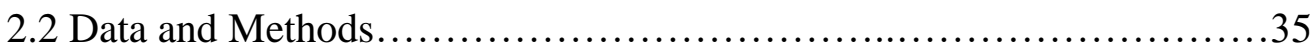

2.2.1 Blue and black marlin occurrence data...........................35

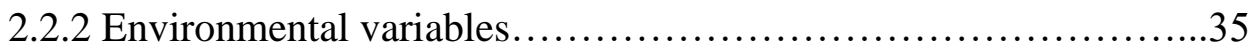

2.2.3 Habitat modeling ...............................................

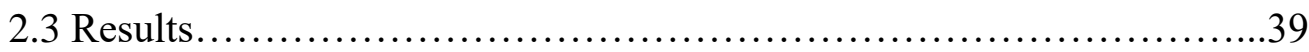

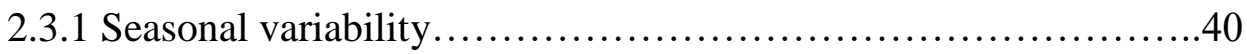

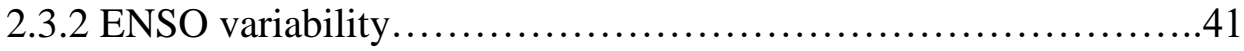

2.3.3 Center of suitable habitat (CSH) .............................42

2.4 Discussion........................................................... 44

2.4.1 Influence of environmental factors................................44

2.4.2 Seasonal distribution patterns................................47

2.4.3 ENSO's impact on distribution patterns..........................49

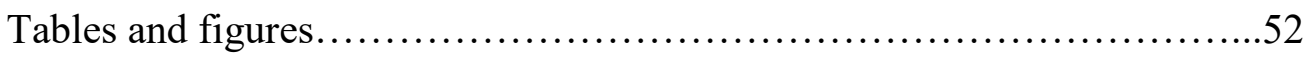

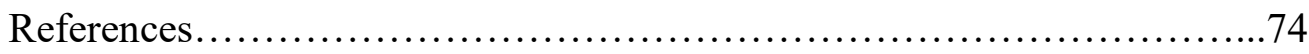

CHAPTER 3: Conclusion...............................................................

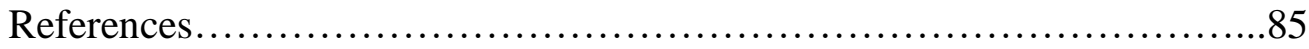




\section{LIST OF TABLES}

Table 2.1 Environmental variables used as covariates in the MaxEnt model.... 52

Table 2.2 Variable contributions (\%) and area under curve (AUC) of the seasonal and El Niño-Southern Oscillation (ENSO) climate simulation for blue marlin (BUM) and black marlin (BLM). The variables that contribute the most to each simulation are highlighted in bold................................. 54

Table 2.3 Analysis of Covariance on the effect seasonality and strength of El Niño-Southern Oscillation (ENSO) and the interaction between seasonality and ENSO on center of suitable habitat 1) latitude and 2) longitude. Oceanic Niño Index (ONI) values were utilized to represent strength of ENSO. A * denotes significance at $\mathrm{p}<0.10, * * \mathrm{p}<0.05, * * * \mathrm{p}<0.01$

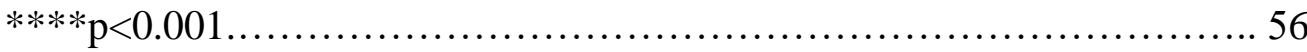




\section{LIST OF FIGURES}

Figure 1.1 Spatial distribution of Blue Marlin (Makaira Nigricans) in the Black Marlin (Istiompax indica) in the Indo-Pacific Ocean taken from Nakamua

Figure 1.2 Surface water currents and masses in the eastern Pacific Ocean. Sea surface temperature data derived from GHRSST L4 AVHRR, Optimum Interpolation and averaged for September - November between 1997-2010. Color gradient represents mean sea surface temperature (red $=$ hot (maximum $\left.=30^{\circ} \mathrm{C}\right)$, blue $=\operatorname{cold}\left(\right.$ minimum $\left.=12^{\circ} \mathrm{C}\right)$

Figure 2.1 (a) Spatial distribution of fishing effort of the tuna purse-seine fishery, and density plots of (b) the distribution of blue marlin (BUM) and (c) black marlin (BLM) occurrence records in the EPO during 1997-2010. Color Scale represents. 58

Figure 2.2 Seasonal distribution of center of suitable habitat (CSH) for BUM and BLM in the EPO from 1997-2010 predicted by the yearly MaxEnt simulations. CSH marked with symbols represent seasons when either a “strong” El Niño or La Niña largely displaced BUM or BLM suitable habitat 
Figure 2.3 Probability of presence of blue marlin as a response to (a) chlorophyll $a$ (CHLA), (b) sea surface temperature (SST), (c) sea surface height (SSH), (d) Zonal current (U), (e) meridional current (V) in the eastern Pacific Ocean under each season (Winter, Spring, Summer, Fall) and Niño condition (El Niño, La Niña, Niño-neutral)..................................... 62

Figure 2.4 Probability of presence of black marlin as a response to (a) chlorophyll $a$ (CHLA), (b) sea surface temperature (SST), (c) sea surface height (SSH), (d) Zonal current (U), (e) meridional current (V) in the eastern Pacific Ocean under each season (Winter, Spring, Summer, Fall) and Niño condition (El Niño, La Niña, Niño-neutral).

Figure 2.5 Seasonal distribution ((a,e) Winter, (b,f) Spring, (c,g) Summer, (d,h) Fall) of habitat suitability for blue marlin (BUM) and black marlin (BLM) in the eastern Pacific Ocean (EPO) predicted by the seasonal climate MaxEnt simulations. Color scale represents the probability of BUM and BLM presence. .66

Figure 2.6 El Niño-Southern Oscillation (ENSO) distribution of habitat suitability for blue marlin (BUM) and black marlin (BLM) in the eastern Pacific Ocean (EPO) predicted by the ENSO climate MaxEnt simulations. Color scale represents the probability of presence of BUM and BLM (a,d) Niño Neutral (b,e) El Niño anomaly from Niño Neutral $(c, f)$ La Niña anomaly from Niño Neutral 
Figure 2.7 El Niño-Southern Oscillation (ENSO) distribution of habitat suitability for BUM and BLM in the EPO predicted by yearly MaxEnt simulations. El Niño and La Niña extremes according to Oceanic Niño Index (ONI) values between 1997-2010. Color scale represents the probability of BUM and BLM presence (a,d) Niño Neutral Fall 2003, (b,e) El Niño Fall 1997, (c,f) La Niña

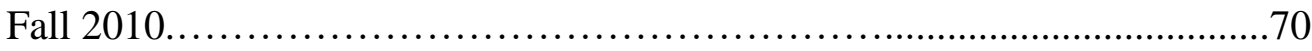

Figure 2.8 Relationship between Niño strength (based on ONI value) and BUM (top panels) and BLM (bottom panels) CSH longitude (left panels) and latitude (right panels). Colors of points and lines define season and shaded areas are 95\% upper and lower confidence levels...........................72 


\begin{abstract}
Overexploitation and climate change can reduce the abundance and shift the spatial distribution of marine species. Determining the habitat suitability of a mobile pelagic species, such as blue marlin (Makaira nigricans) and black marlin (Istiompax indica), can help describe their spatiotemporal distribution patterns over a broad spatial scale, which is a crucial need for fisheries management. Using 14 years (1997-2010) of Inter-American Tropical Tuna Commission (IATTC) catch data from purse-seine vessels in the eastern Pacific Ocean (EPO), we modeled the dynamic habitat suitability of blue and black marlin in response to environmental variables within the EPO using a species distribution model (MaxEnt) with occurrence data $(n=29,711)$ matched with high resolution remotely sensed oceanographic data. The spatial distribution of suitable habitat for blue and black marlin varied seasonally and in response to El Niño-Southern Oscillation (ENSO) and correlated positively with chlorophyll-a concentrations and sea surface temperature. Seasonal suitable habitat shifted between coastal (winter and spring) and oceanic (summer and fall) waters. During La Niña events, habitat suitability extended well offshore along the equator, whereas during El Niño suitable habitat shifted nearshore to the northern and southern waters of the EPO. Analyses on species' centers of distribution revealed that the strength of ENSO events had a strong influence on displacing both species distribution closer or further from shore. Our findings suggest that if climate change continues in the EPO, the suitable habitat of mobile pelagic species may shift shoreward,
\end{abstract}


potentially making them more accessible to recreational anglers and increasing mortality rates. 


\section{CHAPTER 1: INTRODUCTION}

\subsection{Taxonomy and Morphology}

In the Pacific Ocean, billfish are some of the largest and fastest predators to inhabit these waters. Belonging to the suborder Xiphiodei, billfish comprise two existing families: Xiphiidae and Istiophoridae. Xiphiidae is a monophyletic group containing the genus swordfish (Xiphias). Istiophoridae holds all other five genera: blue marlin (Makaira), sailfish (Istiophorus), black marlin (Istiompax), striped and white marlin (Kajikia), and four spearfishes (Tetrapturus) (Collette et al. 2006). The remainder of this study will focus specifically on the blue marlin (BUM) (Makaira nigricans) and the black marlin (BLM) (Istiompax indica).

The physical adaptations of both the BUM and BLM make these top predators highly specialized for life in the pelagic oceans. Marlin are capable of exceptionally high maximum swimming speeds, exceptionally high sustained speeds, and very efficient swimming, because of their anatomy (Brill 1996). A marlin's body shape is fusiform; the body is compressed at the sides and tapers more at the tail than the head (Magnusson et al. 1978). They also have stiff, large crescent shaped tails. This structures them to be highly streamlined, which minimizes both form and friction drag (Davie 1990, Brill 1996). Additionally, both BUM and BLM possess brain and eye heater organs that maintain the temperature of critical tissues considerably warmer than that of the surrounding water (Block et al. 1992). Without this cranial endothermy, marlin would not be able to make feeding migrations into cold waters beneath the thermocline as their 
vision may get impaired, limiting their ability to capture prey (Tullis et al. 1991, Block et al. 1992, Fritsches et al. 2003).

In addition to their body shape, marlins are recognized for is their uniquely extended rostrum, or more commonly referred to as a bill. Each species of billfish has a bill structurally different from the other. As for the BUM and BLM, their bills are extremely stout and round in cross-section (Nakamura 1983). The primary function of this structure is still a subject of speculation, but several of studies have reported different functional uses. One functional use of the bill is as a weapon for prey capture by striking (Nakamura 1983) or spearing prey (van der Elst 1981). Previous studies of marlin stomach contents have reported injury on the bodies of the prey fish found in the stomach of billfish (Shimose et al. 2007). With the use of high-speed video-analysis, Domenici et al. (2014) observed billfish to use their bills to either tap on individual prey targets or to slash through schools in order to isolate their prey for easier capture. However, recent studies on billfish stomach contents have observed the prey's body to be injury-free (Vaske Jr et al. 2011), which brings into question whether bills are necessary to capture prey. Alternatively, it has been suggested that the function of the bill is to reduce drag while swimming (Aleev 1969, Videler 1993).

Although BUM and BLM have similar body plans, each have species specific features that make them distinct. First, BUM pectoral fins may be adducted against its body whereas BLM pectoral fins are rigid and nonadductable (Davie 1990). Additionally, the insertion of a BLM's second dorsal fin is cranial of the insertion of the second anal fin (Davie 1990). BUM second dorsal 
fin, however, is more caudal than second anal fin (Davie 1990). Lastly, BLM have a simple single lateral line where as Indo-Pacific BUM have a looped lateral line pattern (Nakamura 1983). Historically, Atlantic BUM were separated from Indo-Pacific BUM based on the pattern of the lateral line (Nakamura 1983); Atlantic BUM have a reticulate pattern, Indo-Pacific BUM have loops. However, there is no evidence to indicate that the two are separate species (Buonaccorsi et al. 2001).

\subsection{Development, reproduction, and sexual maturity}

Information of a marine organism's life history is critical for understanding their population dynamics and generating effective fisheries management (Sun et al. 2009, Sun et al. 2015). BUM and BLM rapid development, sexual dimorphism, and large size make it difficult to determine their age and growth. Traditionally length - weight relationships were used to estimate age and growth (Skillman and Yong 1974), however, more recent developments have shown the potential of hard parts, such as otoliths, and dorsal and anal fin spines, to assess development (Hill et al. 1989, Wilson et al. 1991, Speare 2003, Sun et al. 2015). Young marlin grow very quickly in length then put on weight later in life. In the first year of development, BUM and BLM can reach up to half of their adult body length (Speare 2003, Sun et al. 2015). For example, at age 1 male and female BLM can approximately grow to a lower-jaw to fork length (LJFL) of $120 \mathrm{~cm}$ and $110 \mathrm{~cm}$, respectively (Speare 2003, Sun et al. 2015). However, as both species age females attain significantly larger sizes (Kume and Joseph 1969, Skillman and Yong 1974, Hill et al. 1989, Wilson et al. 1991, 
Speare 2003, Sun et al. 2015). Previous studies have observed BUM and BLM males to not usually exceed $160 \mathrm{~kg}$ and $260 \mathrm{~cm}$ while females can reach upwards to $700 \mathrm{~kg}$ and $445 \mathrm{~cm}$ (Nakamura 1972, Hill et al. 1989, Wilson et al. 1991, Speare 2003, Sun et al. 2015). These sex-related size differences (sexual dimorphism) is also exhibited at the time of maturity. For BUM size at maturity appears to vary across different regions. In the western Pacific Ocean (WPO) female eye-to-fork length (EFL) at 95\% maturity is approximately $194 \mathrm{~cm}$ whereas for males it is $130 \mathrm{~cm}$ (Sun et al. 2009). However, size at maturity is larger in the EPO with males often being smaller than $220 \mathrm{~cm}$ EFL, but all BUM $230 \mathrm{~cm} \mathrm{EFL}$ and larger are female (Kume and Joseph 1969). Currently it is unknown what BLM sizes are at maturity in the Pacific Ocean or if they vary across different regions, but in the Indian Ocean females and males at 50\% maturity have been observed to be around $100 \mathrm{~kg}$ and 50 to $80 \mathrm{~kg}$, respectively (Cyr 1990).

Several hypothesis have been proposed to explain this sexual dimorphism in BUM and BLM; 1) sex-specific mortality rate (Skillman and Yong 1974, Sun et al. 2015) or 2) sex-specific growth rates (Wilson et al. 1991). Determining sagittae weight is proportional to age in BUM, Wilson et al. (1991) concluded that sexual dimorphism in BUM was due to sexually dimorphic growth rather than sexually dimorphic mortality. Wilson et al. (1991) observed that although female BUM attain larger sizes than males, male and female BUM are equally long lived (>20 years) based on the maximum otolith weight observed for each sex.

Opposite to BUM, Sun et al. (2015), reported that the slight differences in BLM 
growth rate could not account for the difference in body size between sexes.

Rather, it is sexually dimorphic mortality between sexes; the maximum estimated age is about 5 years for male and 11 years for female.

Both species show differences in their reproduction. BUM have a large spawning region that spans from the northern waters $\left(10^{\circ} \mathrm{N}-30^{\circ} \mathrm{N}\right)$ of the WPO from May to October, and travels to the south/southeastern waters of the EPO (south of $10^{\circ} \mathrm{S}$ ) from November to March (Howard and Ueyanagi 1965, Shimose et al. 2008). In the EPO, BUM larvae are scarce east of $140^{\circ} \mathrm{W}$, and most abundant west of $150^{\circ} \mathrm{W}$ (Nishikawa 1985). Additionally, histological studies have shown that BUM oocytes develop asynchronously and that they are multiple spawners, spawning once every 2 to 3 days on average (Sun et al. 2009). BUM are also highly fecund. The batch fecundity of BUM is size related, and fecundity has been seen to increase nonlinearly with body size (Sun et al. 2009). Therefore, batch fecundity for BUM can range from 2.11 to 13.5 million eggs (Sun et al. 2009).

BLM spawning regions are exclusive only in the WPO. The presence of gravid females, and in some cases larvae, have suggested that seasonal aggregations of BLM off the Great Barrier Reef (October - December), Taiwan (AugustOctober), and Hainan island (May-June) may be spawning aggregations (Nakamura 1985, Domeier and Speare 2012). The reproductive biology of BLM the Pacific Ocean are also poorly understood, however, BLM the in Indian Ocean have been observed to be highly fecund batch spawners, producing up to 40 million eggs (Cyr 1990). 


\subsection{Feeding ecology}

Previous studies on BUM and BLM feeding ecology have demonstrated their diet composition, feeding habitat, and behavior. BUM and BLM are apex predators in the food chain. Both species are opportunistic feeders consuming a wide range of prey (Nakamura 1985, Shimose et al. 2006, Shimose et al. 2008, Shimose et al. 2010). Stomach content analysis revealed dietary overlap among the two species eating primarily Scombridae i.e. skipjack, yellowfin, and bigeye (Nakamura 1985, Shimose et al. 2006, Shimose et al. 2008, Shimose et al. 2010). Important prey species, however, can differ from region to region, reflecting the prey availability in each region. For example, Scombridae spp. is the most important prey species, especially skipjack tuna for BUM, in the CPO, WPO, ETPO, and off New Zealand whereas Auxis spp. such as bullet tuna and frigate tuna is most important off California (Baker 1966, Strasburg 1970, Brock 1984, Abitia-Cardenas et al. 1999, Shimose et al. 2006, Shimose et al. 2010). Additionally, due to BUM and BLM wide geographic distributions both species may partition resources if they are inhabiting the same area (Shimose et al. 2006, Shimose et al. 2008). Around Yonaguin Island off southwestern Japan significant contributors to BUM diet are skipjack tuna and a variety of squid but for BLM it is skipjack and mackerel scad (Shimose et al. 2006, Shimose et al. 2008).

Behaviorally, BUM and BLM have been observed to use their bills to feed by stunning individuals in schools of prey (van der Elst 1981, Nakamura 1985, Shimose et al. 2007, Domenici et al. 2014). Additionally, both species feed primarily near the surface, however, previous studies have seen both diving to 
deep, colder waters during the day to forage (Holland et al. 1990, Block et al. 1992, Goodyear et al. 2008, Chiang et al. 2015). Shimose et al. (2006) observed this diving behavior was more frequently by smaller BUM as presence of mesopelagic fish was rarely seen in the stomach content of large BUM. No differences in vertical movement between small and large BUM have been reported, however, the large variety of prey species found in small BUM may reflect their movement to deeper depths, thus more frequent encounters with a diversity of prey. Shimose et al. (2006) hypothesized that small BUM greater vertical movements may be due to not being able to capture Scombridae prey near the surface as they can swim fast.

\subsection{Geographic distribution and habitat}

BUM and BLM are epipelagic species that are geographically distributed throughout the Indo-Pacific Ocean (Nakamura 1985) (Figure 1.1). In the Pacific Ocean, BLM have been observed occasionally entering subtropical waters, whereas BUM are more tropical and more densely distributed in low latitudinal areas (Howard and Ueyanagi 1965, Nakamura 1985).

Both species exhibit spatiotemporal variations in abundance and distribution in the Pacific Ocean as a result from multiple factors (Howard and Ueyanagi 1965). Previous studies have observed both species to undertake seasonal migrations between higher latitude waters in the summer season and low latitudes in the winter season of both hemispheres (Howard and Ueyanagi 1965, Su et al. 2008, Chiang et al. 2015, Carlisle et al. 2017). For BUM, high density 
areas are in northwest Pacific $\left(10^{\circ} \mathrm{N}-30^{\circ} \mathrm{N}\right)$ from May through September and in the southeast Pacific (south of $10^{\circ} \mathrm{S}$ ) from November through March, often moving across the equator $\left(160^{\circ} \mathrm{E}-170^{\circ} \mathrm{W}\right)$ during transitional months of April and October (Howard and Ueyanagi 1965). This northwest - southeast migration in the Pacific Ocean is considered to indicate shifts in accordance with the seasonal change of rising SST progressing in the direction from west to east, and also to be related to spawning (Howard and Ueyanagi 1965). BLM have been observed to have high seasonal densities in several regions of the WPO such as the east China Sea, northwest Coral Sea, Sulu Sea, Celebus Sea, and Taiwan. However, as previous mentioned seasonal aggregations off the Great Barrier Reef (October - December), Taiwan (August - October), and Hainan Island (May June) are thought to be spawning aggregations. BLM seasonal occurrence in other waters may be due to foraging as they have been observed to migrate northward from May to September and southward after October in pursuit of schools of Scombe spp. in the east China Sea (Koto 1959, Morita 1960). There are occurrences of BLM in the EPO, however, little is known about their distribution and concentration in these waters.

Furthermore, BUM and BLM exhibit diel vertical migration throughout the water column. Previous studies using pop up satellite tags and archival tags observed patterns where both species remain in shallow, warm waters during night, and spend more time moving throughout the water column, occasionally taking dives into deeper, colder depths during the day (Holland et al. 1990, Prince and Goodyear 2006, Chiang et al. 2015, Carlisle et al. 2017). Majority of the time 
is spent within the euphotic zone $(<50 \mathrm{~m})$ of the water column, however, during these deep dives both species can reach as the bottom of the mid- layer depth (Holland et al. 1990, Prince and Goodyear 2006, Chiang et al. 2015, Carlisle et al. 2017). This deep diving behavior has been associated with foraging. Temperature and hypoxia have both been documented to limit the vertical distribution of BUM and BLM (Holland et al. 1990, Brill and Lutcavage 2001, Prince and Goodyear 2006, Chiang et al. 2015, Carlisle et al. 2017). Carlisle et al. (2017) saw that vertical habitat compression is greatest when both oxygen and temperature limitations co-occur.

BUM and BLM both have environmental preferences that have influence on their spatiotemporal distributions, which can vary seasonally or by longer phases such as El-Nino Southern Oscillation (ENSO). Previous studies have indicated that both species primarily inhabit oceanic waters of the Pacific Ocean where sea surface temperatures are between $24^{\circ} \mathrm{C}$ and $30^{\circ} \mathrm{C}$, chlorophyll-a concentrations are $<1 \mathrm{mg} / \mathrm{m}^{3}$, and there is a deep mixed layer depth (Holland et al. 1990, Graves et al. 2002, Prince and Goodyear 2006, Su et al. 2008, Stramma et al. 2012, Chiang et al. 2015, Carlisle et al. 2017). Of these environmental factors, studies have suggested that sea surface temperature has the most influence on the spatial distribution of both species in the Pacific Ocean (Holland et al. 1990, Graves et al. 2002, Prince and Goodyear 2006, Boyce et al. 2008, Su et al. 2008, Chiang et al. 2015, Carlisle et al. 2017). However, the data from these studies do not give a good representation of the entire distribution of BUM and BLM in the EPO as they are from electronic tags off Hawaii or longline fisheries 
data which fish in more oceanic waters. A recent study using data from recreation fisheries concluded that chlorophyll-a was the most influential environmental factor on BLM distribution in more near shore regions (Hill et al. 2016). Given that these contradictory findings may be due to limitations in spatial distribution of effort, there is a glaring need to better discern the environmental factors that influence BUM and BLM distribution at a broad scale.

\subsection{Oceanography of the eastern Pacific Ocean}

\subsubsection{Surface currents and water masses}

The EPO is a dynamic region with a unique oceanography. The primary surface currents comprising the current system in the WPO are the north equatorial current (NEC), located at about $10^{\circ} \mathrm{N}-15^{\circ} \mathrm{N}$, the south equatorial current (SEC), which overlaps the equator about $15^{\circ} \mathrm{S}-7^{\circ} \mathrm{N}$, the north equatorial counter-current (NECC) at about $3^{\circ} \mathrm{N}-10^{\circ} \mathrm{N}$, and the California and Peru current that slow adjacent to the west coast of the North American and South American continents, respectively (Hinton 2015) (Figure 1.2). This equatorial current system is driven by energy transfer to the ocean surface by the north and south easterly trade winds that circle the globe between about $30^{\circ} \mathrm{N}$ and $30^{\circ} \mathrm{S}$ and converge at the Inter-Tropical Convergence Zone (ITCZ). Additionally, these surface currents are induced by the Coriolis Effect; the earth's rotation acting on wind and ocean currents to move perpendicular to the direction of motion and to the axis of rotation. On earth, the Coriolis Effect causes westward flowing currents to deflect to the right in the northern hemisphere and left in the southern 
hemisphere. Therefore, the NEC and SEC are redirected to poles creating the western-boundary Kuroshio and the Eastern Australian currents, respectively (Hinton 2015). In the north Pacific Ocean, the Kuroshio current flows into the North Pacific current eventually striking the North American continent, which redirects southward, and giving rise to the California current. The California current then merges into the NEC. The opposite is seen in the southern pacific. As the eastern Australian current flows southward, it merges into the Antarctic Circumpolar Current, and eventually strikes the South American continent. This redirects the flow of the current north as the Peru Current, which merges into the SEC (Hinton 2015). In addition to multiple surface currents, the EPO is comprised of three types of water masses: Sub-tropical Surface Water, Tropical Surface Water, and Equatorial Surface Water (Wyrtki 1966). The Sub-Tropical Surface Water is formed in regions where evaporation exceeds precipitation, thus producing high salinity ( $>35 \mathrm{ppt}$ ) in water temperature ranging between $28{ }^{\circ} \mathrm{C}$ to $15{ }^{\circ} \mathrm{C}$ (Wyrtki 1966). The Tropical Surface Water has high water temperature as well $\left(>25^{\circ} \mathrm{C}\right)$, but less salinity ( $\left.<34 \mathrm{ppt}\right)$ (Wyrtki 1966). Equatorial Surface Waters is lies between the two other waters masses, giving this water mass intermediate properties (water temperature: $<25^{\circ} \mathrm{C}$; Salinity: $>34 \mathrm{ppt}$ ) (Wyrtki 1966).

The winds and surface currents in the EPO influence the oceanography of the EPO zonally and meridionally. The thermocline is the location in the water column at which the change in temperature with increasing depth is the greatest (Hinton 2015). At the equator, the zonal, or east to west, thermocline structure 
shoals from a depth of about $200 \mathrm{~m}$ at $160^{\circ} \mathrm{E}$ to $40 \mathrm{~m}$ at $90^{\circ} \mathrm{W}$ (Hinton 2015). The meridional, north to south, thermocline structure follows a trend where from the south the thermocline shoals from about $250 \mathrm{~m}$ at $17^{\circ} \mathrm{S}$ to about $90 \mathrm{~m}$ when under the NECC (Hinton 2015). Thereafter, it descends as it passes beneath the NEC (Hinton 2015). The EPO is also characterized to have a strong, shallow oxygen minimum zone (OMZ) which has been observed to have lower oxygen concentrations than most other low oxygen areas in the world ocean (Fiedler and Talley 2006). The depth of the OMZ is closely linked to the depth of the thermocline via decaying organic matter sinking below the thermocline from high production areas above producing oxygen depleted waters beneath the thermocline (Hinton 2015). This combination of shallow thermocline and OMZ can limit the vertical distribution of zooplankton and fish are restricted to secondary production (Fernández-Álamo and Färber-Lorda 2006, Hinton 2015).

\subsubsection{Productivity and seasonal variations}

The EPO is a highly productive region, producing about $22 \%$ of the primary production in the Pacific Ocean, while only covering about $18 \%$ of the Pacific Ocean (Hinton 2015). In most oceans, primary production is limited by the availability of nutrient and/or light, but in the EPO it is iron-limited (Pennington et al. 2006). In the EPO three regions of primary production are upwelling regions along the coast, upwelling regions at the equator (equatorial cold tongue), and the Costa Rica Dome. 
The seasonal changes in oceanography and productivity of the EPO is highly influenced on the seasonal meridional migration of the ITCZ. The ITCZ reaches its southernmost position, about $5^{\circ} \mathrm{N}$, during the boreal winter and much of spring, which as a result intensifies the northeasterly trade winds and the Tehuatepec, Papagayo, and Panama jets strengthen (Amador et al. 2006). These strong winds advect surface waters westward, allowing deep nutrient rich waters to be upwelled to the surface producing highly productive waters, particularly in more coastal regions, such as waters off Peru. This seasonal Peruvian coastal upwelling has its highest levels of chlorophyll and primary production during the boreal winter and spring (Pennington et al. 2006), which help support the largest fishery in the world (Lavín et al. 2006). Additionally, the strengthening of the Tehuatepec, Papagayo, and Panama jets produce both cyclonic and anticyclonic eddies in the region off Guatemala interrupting the warm, low productivity of the eastern Pacific warm pool (Willett et al. 2006), advecting relatively high chlorophyll waters in the gulfs and to the west (Lavín et al. 2006). The eastern Pacific warm pool is an area where the convergence of the trade winds on the ITCZ leaves a "shadow" zone to the west of Mexico and Central America where the wind is weak (Lavín et al. 2006). As a result, this area has high SSTs and nutrient poor waters due to the high stratification and diminished vertical mixing (Fiedler and Talley 2006, Pennington et al. 2006). However, during the season of the wind jets these waters become cooler and more productive (Pennington et al. 2006). 
In the boreal summer and fall months, the ITCZ reaches its northernmost position most latitude, about $10^{\circ} \mathrm{N}$, which weakens the upwelling winds, jets, and formation of eddies that peak in the boreal winter and spring in the EPO (Pennington et al. 2006). As a result, waters that were once highly productive coastal waters become reduced. However, during this period the equatorial cold tongue, an open-ocean upwelling region between the equator and $10^{\circ} \mathrm{N}$ in the EPO continues to be productive. Its coldest and most productive period in September, when upwelling is strongest (Pennington et al. 2006) and in the summer and fall, phytoplankton and zooplankton biomass are maximal in this region (Fernández-Álamo and Färber-Lorda 2006). Lastly, the Costa Rica Dome, another open-ocean upwelling region that has relatively high primary and secondary production, does not exhibit large seasonal variations in SSTs or

productivity (Pennington et al. 2006). However, the Costa Rica Dome does exhibit seasonal variations in its extent as it extends up to $600 \mathrm{~m}$ to the west in the boreal summer and fall (Fiedler and Talley 2006, Kessler 2006).

\subsubsection{ENSO}

The unique oceanography of the EPO is heavily influenced by ENSO, which is arguably the most significant source of temporal variability in the tropical waters of the EPO (Pennington et al. 2006). ENSO is the cycle between El Niño, La Niña, and Niño neutral states as atmospheric pressure changes across the Pacific. The El Niño events are triggered by weakening or reversal of the coastal trade winds in the western Pacific in response to the atmospheric pressure in the western Pacific increasing while that in the EPO decreases. As a result, the 
physical effects of El Niño involve weakening or reversal of the westwardflowing NEC and SEC, and a strengthening of the NECC advecting warm waters of the west Central Pacific into the EPO and along the coast of South America (Kessler 2006, Hinton 2015). There is also an increase in sea surface height (SSH) in the EPO which causes a deepening of the thermocline and nutricline, thus suppressing primary production (Pennington et al. 2006). Although upwelling in the cold tongue, the Costa Rica Dome, and off Peru continued, the upwelled waters come from the warm and nutrient-poor upper layer (Pennington et al. 2006), which consistently diminish the productivity in these areas. During El Niño, diminished primary production and the deepened thermocline have detrimental effects on the survival and reproduction, and affect the distribution of higher trophic level organisms (Ballance et al. 2006). This diminished productivity during an El Niño has been observed to have negative effects on fisheries, especially in Peru where the anchoveta fishery crashes (Lavín et al. 2006). Opposite to El Niño's, La Niña events are associated with a strengthened westward flow of the Southern Equatorial Current which leads to increased equatorial upwelling, shoaling of the thermocline and nutricline, and an overall extension of the equatorial cold tongue from the Eastern Pacific into the Central Pacific (Pennington et al. 2006, Carlisle et al. 2017).

\subsection{Eastern Pacific Ocean Tuna Purse-Seine Fishery}

In the eastern Pacific Ocean, marlin and other billfish are taken by fisheries of many nations which direct their effort for tunas between about $50^{\circ} \mathrm{N}$ and $50^{\circ} \mathrm{S}$ (IATTC, 2015). The majority of the catch of BUM and BLM are made 
by longline fisheries, which are targeting bigeye and yellowfin tuna, while lesser amounts are caught by recreational fisheries and various other commercial surface fisheries, such as purse-seines (Hinton, 2001).

Today, the EPO fishery is dominated by purse-seine fleets. Previously, pole-and-line vessels dominated in the EPO in coastal regions and near offshore island and banks (IATTC, 2015). However, during the late 1950s and early 1960s, the majority of pole-and-line vessels were converted to purse-seiners (IATTC, 2015). From 1961 to 2015, purse-seine vessels increased from 125 to 243 vessels, and their total well volume increased from 32 thousand to 248 thousand $\mathrm{m}^{3}$ (IATTC, 2015). This increase in well volume occurred when U.S-flag vessels left the EPO. This was due to the U.S. tuna-canning industry adopting a policy of not purchasing tunas caught on trips associated with dolphins. As a result, vessels of other nations moved to the EPO and in 2015, the fleet was dominated by vessels operating under Ecuadorian (37\%) and Mexican flags (23\%) (IATTC, 2015). Currently, purse-seine vessels fish for tuna via three different methodologies: the net may be set (1) around schools of tuna associated with dolphins (dolphin sets), (2) around schools of tuna associated with logs or other floating objects (log sets), or (3) around unassociated schools of tuna (school sets). With the rise in popularity of Dolphin-Safe Tuna, fish-aggregating devices (FADs), a type of log set, have become of relative importance to purse-seine fishing effort. Their use has reached to $97 \%$ of all floating object sets by vessels with $>363$ metric tons carrying capacity (IATTC, 2015). 
As previously mentioned, there is a single stock of BUM the Pacific Ocean (Hinton, 2001). The biomass of this stock has fluctuated several times over the last 60 years. In 1951-1952 the annual catch of Pacific BUMe was about 11,000 metric tons (Hinton, 2001). As fisheries for tunas grew, simultaneously the annual catch of BUM rapidly increased, peaking at about 38,000 metric tons by 1962-1963 (Hinton, 2001; BWG, 2013). In the early 1970's, the development of deep set longline gear configuration, deploying hooks deeper in the water column and out of the habitat range of BUM, resulted in the average annual catch decreasing to about 12,300 metric tons (Hinton, 2001; BWG, 2013). Over the next couple of decades, annual catch began to increase, reporting the highest catch in 1993 of 25,509 metric tons (Hinton, 2001; BWG, 2013). Yet, after the decrease in effort by Japanese longline fishery, annual catch as of 2011 has been reported to be maintained to around 18,000 metric tons (BWG, 2013). The status of BUM in the Pacific Ocean remains unknown. One assessment concluded that the stock is healthy condition (Hinton 2001) though likely fully exploited (Kleiber et al. 2003). There has never been an assessment of the BLM stock in the Pacific. There has never been an assessment of the BLM stock in the Pacific. Therefore, there is a clear need for a better understanding of the stock structure for these species to assess if the stocks of both species are being close to fully exploited, overexploited, or in a healthy state.

\subsection{Objective and Hypotheses}

The objective of this study was to fill in crucial ecological information gaps in the understanding of what environmental factors influence BUM and 
BLM distribution as well as provide a clearer picture of the spatiotemporal distribution of BUM and BLM in the EPO. Understanding the spatiotemporal distributions, habitat uses, and environmental preferences is necessary for generating effective management strategies and can be utilized to predict spatial distributions of BUM and BLM if oceans continue to warm. This was accomplished by constructing species distribution models from a 14-year time series (1997-2014), and addressing the following questions:

1. How do the presence of BUM and BLM relate to sea surface temperature, chlorophyll a, sea surface height, and currents?

$\mathrm{H}_{0}$ : There is no significant relationship between presence of BUM and BLM and to sea surface temperature, chlorophyll a, sea surface height, and currents.

2. How do variations in environmental conditions (sea surface temperature, chlorophyll a, sea surface height, and currents) influence the spatiotemporal distribution of suitable habitat for BUM and BLM the EPO?

$\mathrm{H}_{0 \mathrm{a}}$ : There will be no significant difference in spatial distribution of BUM and BLM suitable habitat as environmental conditions vary. $\mathrm{H}_{0 \mathrm{~b}}$ : There is no correlation between time and the distribution of BUM and BLM suitable habitat. 
Figure 1.1 Spatial distribution of Blue Marlin (Makaira Nigricans) in the Black Marlin (Istiompax indica) in the Indo-Pacific Ocean taken from Nakamua (1985). 

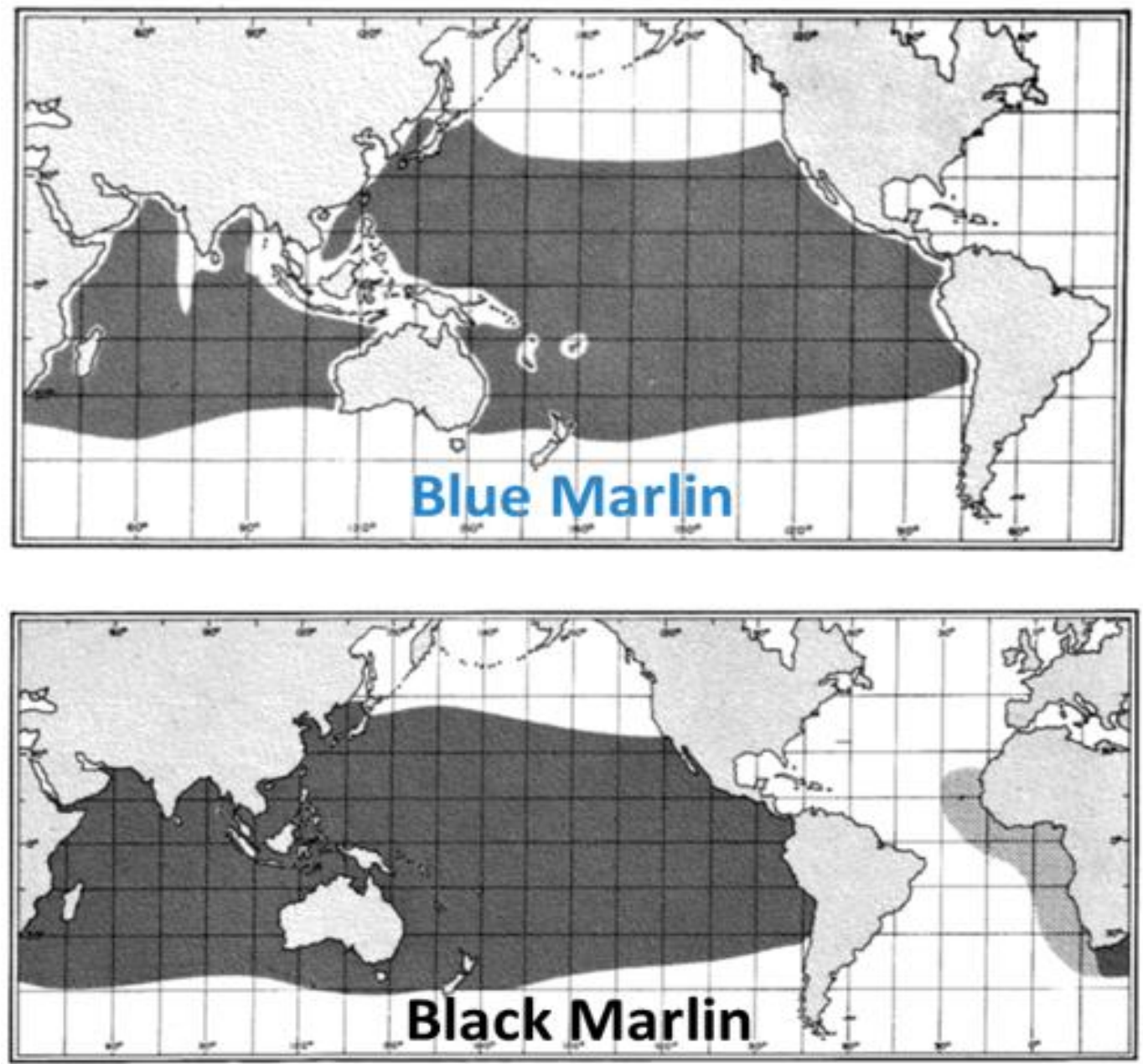
Figure 1.2 Surface water currents and masses in the eastern Pacific Ocean. Sea surface temperature data derived from GHRSST L4 AVHRR, Optimum Interpolation and averaged for September - November between 1997-2010. Color gradient represents mean sea surface temperature $\left(\right.$ red $=$ hot $\left(\right.$ maximum $\left.=30^{\circ} \mathrm{C}\right)$, blue $=\operatorname{cold}\left(\right.$ minimum $\left.=12^{\circ} \mathrm{C}\right)$. 


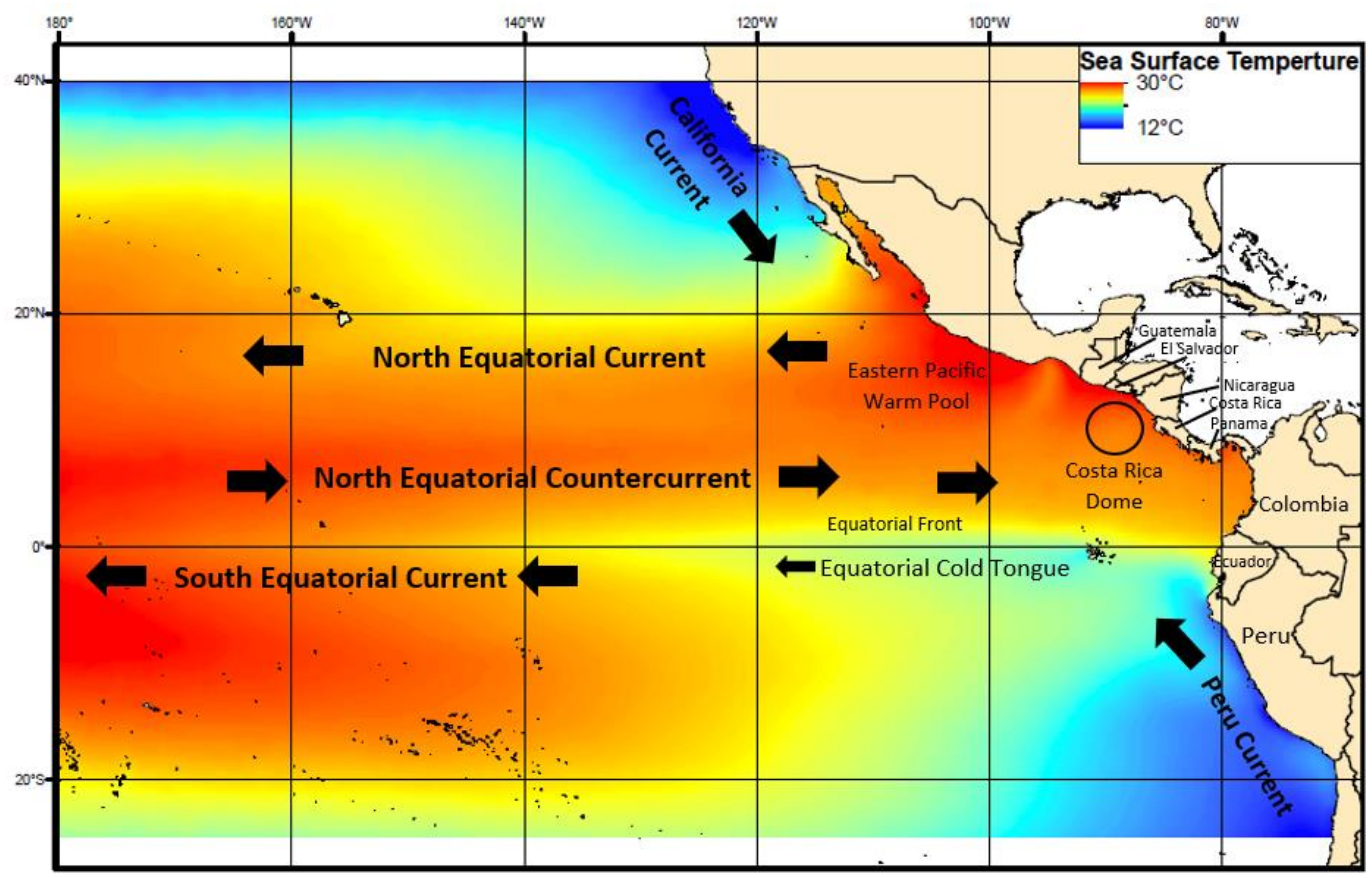




\section{References}

Abitia-Cardenas, L. A., F. Galvan-Magaña, F. J. Gutierrez-Sanchez, J. RodriguezRomero, B. Aguilar-Palomino, and A. Moehl-Hitz. 1999. Diet of blue marlin Makaira mazara off the coast of Cabo San Lucas, Baja California Sur, Mexico. Fisheries Research 44:95-100.

Aleev, I. U. 1969. Function and gross morphology in fish. Function and gross morphology in fish.

Amador, J. A., E. J. Alfaro, O. G. Lizano, and V. O. Magaña. 2006. Atmospheric forcing of the eastern tropical Pacific: A review. Progress in Oceanography 69:101-142.

Baker, A. N. 1966. Food of marlins from New Zealand waters. Copeia:818-822.

Ballance, L. T., R. L. Pitman, and P. C. Fiedler. 2006. Oceanographic influences on seabirds and cetaceans of the eastern tropical Pacific: a review. Progress in Oceanography 69:360-390.

Block, B., D. Booth, and F. Carey. 1992. Depth and temperature of the blue marlin, Makaira nigricans, observed by acoustic telemetry. Marine Biology 114:175-183.

Boyce, D. G., D. P. Tittensor, and B. Worm. 2008. Effects of temperature on global patterns of tuna and billfish richness. Marine Ecology Progress Series 355:267-276.

Brill, R. W. 1996. Selective advantages conferred by the high performance physiology of tunas, billfishes, and dolphin fish. Comparative Biochemistry and Physiology Part A: Physiology 113:3-15.

Brill, R. W., and M. E. Lutcavage. 2001. Understanding environmental influences on movements and depth distributions of tunas and billfishes can significantly improve population assessments. Pages 179-198 in American Fisheries Society Symposium. American Fisheries Society.

Brock, R. E. 1984. A contribution to the trophic biology of the blue marlin (Makaira nigricans Lacépède, 1802) in Hawaii.

Buonaccorsi, V., J. McDowell, and J. Graves. 2001. Reconciling patterns of interocean molecular variance from four classes of molecular markers in blue marlin (Makaira nigricans). Molecular Ecology 10:1179-1196. 
Carlisle, A. B., R. E. Kochevar, M. C. Arostegui, J. E. Ganong, M. Castleton, J. Schratwieser, and B. A. Block. 2017. Influence of temperature and oxygen on the distribution of blue marlin (Makaira nigricans) in the Central Pacific. Fisheries Oceanography 26:34-48.

Chiang, W.-C., M. K. Musyl, C.-L. Sun, G. DiNardo, H.-M. Hung, H.-C. Lin, S.C. Chen, S.-Z. Yeh, W.-Y. Chen, and C.-L. Kuo. 2015. Seasonal movements and diving behaviour of black marlin (Istiompax indica) in the northwestern Pacific Ocean. Fisheries Research 166:92-102.

Collette, B. B., J. R. McDowell, and J. E. Graves. 2006. Phylogeny of recent billfishes (Xiphioidei). Bulletin of Marine Science 79:455-468.

Cyr, E. 1990. Age, growth, and reproduction of blue marlin and black marlin from the Indian Ocean. Planning the future of billfishes. Research and management in the 90 s and beyond.

Davie, P. S. 1990. Pacific marlins: anatomy and physiology.

Domeier, M. L., and P. Speare. 2012. Dispersal of adult black marlin (Istiompax indica) from a Great Barrier Reef spawning aggregation. PloS one 7:e31629.

Domenici, P., A. D. M. Wilson, R. Kurvers, S. Marras, J. E. Herbert-Read, J. F. Steffensen, S. Krause, P. E. Viblanc, P. Couillaud, and J. Krause. 2014. How sailfish use their bills to capture schooling prey. Proceedings of the Royal Society B-Biological Sciences 281:6.

Fernández-Álamo, M. A., and J. Färber-Lorda. 2006. Zooplankton and the oceanography of the eastern tropical Pacific: a review. Progress in Oceanography 69:318-359.

Fiedler, P. C., and L. D. Talley. 2006. Hydrography of the eastern tropical Pacific: A review. Progress in Oceanography 69:143-180.

Fritsches, K. A., N. J. Marshall, and E. J. Warrant. 2003. Retinal specializations in the blue marlin: eyes designed for sensitivity to low light levels. Marine and Freshwater Research 54:333-341.

Goodyear, C. P., J. Luo, E. D. Prince, J. P. Hoolihan, D. Snodgrass, E. S. Orbesen, and J. E. Serafy. 2008. Vertical habitat use of Atlantic blue marlin Makaira nigricans: interaction with pelagic longline gear. Marine Ecology Progress Series 365:233-245. 
Graves, J. E., B. E. Luckhurst, and E. D. Prince. 2002. An evaluation of pop-up satellite tags for estimating postrelease survival of blue marlin (Makaira nigricans) from a recreational fishery. Fishery Bulletin 100:134-142.

Hill, K. T., G. M. Cailliet, and R. L. Radtke. 1989. A comparative analysis of growth zones in four calcified structures of pacific blue marlin, Makaim. Fishery Bulletin 87.

Hill, N. J., A. J. Tobin, A. E. Reside, J. G. Pepperell, and T. C. Bridge. 2016. Dynamic habitat suitability modelling reveals rapid poleward distribution shift in a mobile apex predator. Global change biology 22:1086-1096.

Hinton, M. 2015. Oceanographic conditions in the EPO and their effect on tuna fisheries.in Inter-Amer. Trop. Tuna Comm. 6th Scient. Adv. Com. Meeting. SAC-06 INF-C.

Hinton, M. G. 2001. Status of blue marlin in the Pacific Ocean. Inter-Amer. Trop. Tuna Comm., Stock Assess. Rep 1:284-319.

Holland, K., R. Brill, and R. K. Chang. 1990. Horizontal and vertical movements of Pacific blue marlin captured and released using sportfishing gear. Fishery Bulletin 88:397-402.

Howard, J. K., and S. Ueyanagi. 1965. Distribution and relative abundance of billfishes (Istiophoridae) of the Pacific Ocean.

Kessler, W. S. 2006. The circulation of the eastern tropical Pacific: A review. Progress in Oceanography 69:181-217.

Kleiber, P., M. G. Hinton, and Y. Uozumi. 2003. Stock assessment of blue marlin (Makaira nigricans) in the Pacific using MULTIFAN-CL. Marine and Freshwater Research 54:349-360.

Koto, T. 1959. Studies on the tuna long line fishery in the East China Sea. IV. Ecological studies on the socalled white marlin, Marlina marlina (Jordan \& Hill). Rep Nankai Reg Fish Res Lab 11:108-129.

Kume, S., and J. Joseph. 1969. Size composition and sexual maturity of billfish caught by the Japanese longline fishery in the Pacific Ocean east of 130W. Far Seas Fisheries Research Laboratory.

Lavín, M., P. C. Fiedler, J. Amador, L. Ballance, J. Färber-Lorda, and A. MestasNuñez. 2006. A review of eastern tropical Pacific oceanography: Summary. Progress in Oceanography 69:391-398. 
Magnusson, J., W. Hoar, and D. Randall. 1978. Locomotion by Scombroid fishes: hy-dromechanics, morphology, and behaviour. Fish Physiology 7:240315.

Morita, T. 1960. Fishing-ground constitutional studies on the white-marlin, Marlina marlina Jordan \& Hill, over the East China Sea. I. On the fishingground constitution occurring with the seasonal change of the environment. Bull Jpn Soc Sci Fish 26:887-893.

Nakamura, I. 1972. Synopsis of the biology of the black marlin, Makaira indica (Cuvier), 1831. Pages 9-12 in Proceedings of the International Billfish Symposium.

Nakamura, I. 1983. Systematics of the billfishes (Xiphiidae and Istiophoridae).

Nakamura, I. 1985. Billfishes of the world: an annotated and illustrated catalogue of marlins, sailfishes, spearfishes, and swordfishes known to date. United Nations Development Programme, Food and Agriculture Organization of the United Nations.

Nishikawa, Y. 1985. Average Distribution of larvae of oceanic species of scombroid fishes. Far Seas Fish. Res. Lab.:1956-1982.

Pennington, J. T., K. L. Mahoney, V. S. Kuwahara, D. D. Kolber, R. Calienes, and F. P. Chavez. 2006. Primary production in the eastern tropical Pacific: a review. Progress in Oceanography 69:285-317.

Prince, E. D., and C. P. Goodyear. 2006. Hypoxia-based habitat compression of tropical pelagic fishes. Fisheries Oceanography 15:451-464.

Shimose, T., H. Shono, K. Yokawa, H. Saito, and K. Tachihara. 2006. Food and feeding habits of blue marlin, Makaira nigricans, around Yonaguni Island, southwestern Japan. Bulletin of Marine Science 79:761-775.

Shimose, T., K. Yokawa, and H. Saito. 2010. Habitat and food partitioning of billfishes (Xiphioidei). Journal of fish biology 76:2418-2433.

Shimose, T., K. Yokawa, H. Saito, and K. Tachihara. 2007. Evidence for use of the bill by blue marlin, Makaira nigricans, during feeding. Ichthyological Research 54:420-422.

Shimose, T., K. Yokawa, H. Saito, and K. Tachihara. 2008. Seasonal occurrence and feeding habits of black marlin, Istiompax indica, around Yonaguni Island, southwestern Japan. Ichthyological Research 55:90-94. 
Skillman, R. A., and M. Y. Yong. 1974. Length-weight relationships for six species of billfishes in the central Pacific Ocean. US Nat. Mar. Fish. Serv., NOAA Tech. Rep. NMFS SSRF-675 (2):126-137.

Speare, P. 2003. Age and growth of black marlin, Makaira indica, in east coast Australian waters. Marine and Freshwater Research 54:307-314.

Stramma, L., E. D. Prince, S. Schmidtko, J. Luo, J. P. Hoolihan, M. Visbeck, D. W. Wallace, P. Brandt, and A. Körtzinger. 2012. Expansion of oxygen minimum zones may reduce available habitat for tropical pelagic fishes. Nature Climate Change 2:33.

Strasburg, D. W. 1970. A report on the billfishes of the central Pacific Ocean. Bulletin of Marine Science 20:575-604.

Su, N. J., C. L. Sun, A. E. Punt, and S. Z. Yeh. 2008. Environmental and spatial effects on the distribution of blue marlin (Makaira nigricans) as inferred from data for longline fisheries in the Pacific Ocean. Fisheries Oceanography 17:432-445.

Sun, C.-L., Y.-J. Chang, Y.-J. Chang, C.-C. Tszeng, C.-C. Tszeng, S.-Z. Yeh, and S.-Z. Yeh. 2009. Reproductive biology of blue marlin (Makaira nigricans) in the western Pacific Ocean. Fishery Bulletin 107:420-432.

Sun, C.-L., S.-Z. Yeh, C.-S. Liu, N.-J. Su, and W.-C. Chiang. 2015. Age and growth of Black marlin (Istiompax indica) off eastern Taiwan. Fisheries Research 166:4-11.

Tullis, A., B. A. Block, and B. D. Sidell. 1991. Activities of key metabolic enzymes in the heater organs of scombroid fishes. Journal of experimental biology 161:383-403.

van der Elst, R. P. 1981. Use of the bill during feeding in the black marlin (Makaira indica). Copeia 1981:215.

Vaske Jr, T., P. Travassos, P. Pinheiro, F. Hazin, M. Tolotti, and T. Barbosa. 2011. Diet of the blue marlin (Makaira Nigricans, Lacepde 1802) (Perciformes: Istiophoridae) of the southwesrtern equatorial Atlantic Ocean. Brazilian Journal of Aquatic Science and Technology:65-70.

Videler, J. 1993. Fish Swimming. London. UK: Chapman \& Hall 45.

Willett, C., R. Leben, and M. Lavin. 2006. Eddies and mesoscale processes in the eastern tropical Pacific: a review. Progress in Oceanography 69:218-238. 
Wilson, C. A., J. M. Dean, E. D. Prince, and D. W. Lee. 1991. An examination of sexual dimorphism in Atlantic and Pacific blue marlin using body weight, sagittae weight, and age estimates. Journal of Experimental Marine Biology and Ecology 151:209-225.

Wyrtki, K. 1966. Oceanography of the eastern equatorial Pacific Ocean. Oceanogr 33:68. 


\section{CHAPTER 2: Habitat Preferences of Blue Marlin (Makaira nigricans) and Black Marlin (Istiompax indica) in the Eastern Pacific Ocean.}

\subsection{Introduction}

Large predatory fish populations and communities have been impacted significantly by industrialized fisheries (Jackson et al. 2001, Myers and Worm 2003, Sibert et al. 2006, Worm et al. 2009). This, coupled with climate change, pollution, and other anthropogenic activities, can put unprecedented pressure on higher trophic level predators, such as tunas, billfishes, or sharks, which may cascade downward through the food web and affect ecosystem functionality (Baum and Worm 2009). Overexploitation may reduce fish abundances (Jackson et al. 2001, Myers and Worm 2003, Coleman et al. 2004, Kitchell et al. 2006, Jensen et al. 2010) while climate change can cause shifts in spatial distribution of marine species (Pinsky et al. 2013, Hill et al. 2016). Currently, regional fishery management organizations are moving away from traditional fisheries objectives, e.g. achieving single-species Maximum Sustainable Yield (MSY), to an ecosystembased or dynamic management framework (Sinclair et al. 2002, Garcia and Cochrane 2005, Maxwell et al. 2015). To improve the conservation and management of these apex predators, it is important to determine and understand their suitable habitat and spatial distribution (Pearce et al. 2001, Hoolihan et al. 2015, Hill et al. 2016). In this study, we used for the first-time presence-only species distribution model (SDM) to better understand habitat use patterns of blue 
marlin (BUM), Makaira nigricans, and black marlin (BLM), Istiompax indica, in the eastern Pacific Ocean (EPO) (Figure 1.2).

BUM and BLM are epipelagic species that are widely distributed throughout the tropical and subtropical waters of the Indo-Pacific Ocean (Nakamura, 1985). While aspects of BUM and BLM spatial distribution in the western Pacific Ocean are relatively well studied (Shimose et al. 2006, Shimose et al. 2012, Chiang et al. 2015, Hill et al. 2016), little is known about their distribution in the EPO. In the Pacific, BUM are typically more tropical and densely distributed in low latitudinal areas, whereas BLM have been observed to occasionally enter subtropical and temperate regions as far south as the Cape of Good Hope (Howard and Ueyanagi 1965, Nakamura 1985). Fisheries data suggest there is a single stock of BUM in the Pacific Ocean that make migrate to the northwest and southeast Pacific Ocean in the boreal summer and winter months, respectively, which could be related to spawning regions (Howard and Ueyanagi 1965, Hinton 2001). The distribution of catches of BLM suggests a single stock centered off Australia with the species widely distributed but not consistently abundant elsewhere (Skillman 1988, Domeier and Speare 2012). Although previous studies on BUM and BLM demonstrated that both species are highly migratory and exhibit trans-basin and trans-oceanic movements (Squire Jr and Nielsen 1983, Hinton 2001, Carlisle et al. 2017), both species show affinity for continental margins and seamounts, increasing their accessibility to recreational anglers (Campbell et al. 2003, Gunn et al. 2003, Morato et al. 2010, Hill et al. 2016). 
BUM and BLM are both highly important resources to commercial and recreational fisheries (Molony 2005, Chiang et al. 2015). Predominately caught in pelagic longline fisheries targeting tuna (Thunnus spp) and swordfish (Xiphias gladius), they are also taken in smaller amounts by purse-seines, harpoons, and gillnets fisheries (Hinton 2001, Chiang et al. 2015). Additionally, both species are prized targets of recreational anglers who fish relatively close to shore in various areas around the Pacific Basin (Kleiber et al. 2003, Pepperell 2011) The status of BUM in the Pacific Ocean remains unknown. One assessment concluded that the stock is healthy condition (Hinton 2001) though likely fully exploited (Kleiber et al. 2003). There has never been an assessment of the BLM stock in the Pacific.

Determining suitable habitat and spatial distribution is highly important in the conservation and management of marine organisms (Pearce et al. 2001, Hoolihan et al. 2015, Hill et al. 2016). However, it may be challenging to discern the spatiotemporal distribution for a mobile species, such as BUM and BLM, in a dynamic marine environment. In the absence of sophisticated tagging data, species distribution models (SDM) have been useful in predicting the spatial distribution of species relative to environmental variables. The most common SDM are regression models, such as logistic general-additive or general-linear models; however, these statistical models require presence/absence data, which are not always readily available from fisheries-dependent samples (Phillips et al. 2006, Elith et al. 2011). In recent years SDM's have been built that utilize presence-only data. The predictive performance of the presence-only SDM's are consistently comparable to presence/absence models (Ehrhardt and Fitchett 2006). 
The environmental preferences and spatial distribution of BUM and BLM, inferred either from electronic tags or longline fisheries data, indicate that both species primarily inhabit oceanic waters of the Pacific Ocean where sea surface temperatures (SST) are between $24^{\circ} \mathrm{C}$ and $30^{\circ} \mathrm{C}$, chlorophyll-a concentrations (CHLA) are $<1 \mathrm{mg} / \mathrm{m}^{3}$, and there is a deep mixed layer depth (Holland et al. 1990, Graves et al. 2002, Prince and Goodyear 2006, Su et al. 2008, Stramma et al. 2012, Chiang et al. 2015, Carlisle et al. 2017). Of these environmental factors, studies have suggest SST has the most influence on the spatial distribution of both species (Holland et al. 1990, Graves et al. 2002, Prince and Goodyear 2006, Boyce et al. 2008, Su et al. 2008, Chiang et al. 2015, Carlisle et al. 2017). In contrast, a recent study using data from recreation fisheries concluded that CHLA was the most influential environmental factor on BLM distribution in more near shore regions (Hill et al. 2016). Given such findings may be due to limitations in spatial distribution of effort and resolution of environmental variables, there is a glaring need to better discern the environmental factors that influence BUM and BLM distribution at a broad scale.

This study provides a unique opportunity to observe BUM and BLM habitat preferences as it utilizes incidental catch data from the tuna purse-seine fishery, which fishes in both coastal and oceanic waters throughout the EPO. In the EPO, habitat availability likely shifts over a variety of spatial and temporal scales due to the seasonal changes this region experiences (Ortega-García et al. 2015, AcostaPachón et al. 2017). Large scale oceanographic changes during El Niño Southern Oscillation (ENSO), events may also impact habitat availability and distribution of 
BUM and BLM in the EPO (Su et al. 2011, Carlisle et al. 2017). The main objectives of this study were to describe the spatiotemporal patterns in habitat suitability of BUM and BLM in the EPO and to identify the most influential environmental factors influencing their spatial patterns, which can provide a basis to manage the fisheries that catch these species.

\subsection{Data and methods}

\subsubsection{Blue and Black Marlin Occurrence Data}

We used opportunistic BUM and BLM occurrence data (incidental catch) collected by Inter-American Tropical Tuna Commission (IATTC) scientific observers aboard EPO tuna purse-seine fishing vessels (Figure 2.1). We analyzed seasonal occurrence data collected between 1997 and 2010 because highresolution, remotely sensed environmental data was available during this period.

The EPO tuna purse-seine fishery does not target BUM or BLM. Therefore, all occurrence records on BUM and BLM may be considered as haphazard samples. Catch data recorded by the scientific observers included: year, month, day, hour, location of capture, marlin species, set type, length of BUM and BLM, and biomass (metric tons). In total, 13,153 BUM and 7,948 BLM occurrence records were collected during this period within the region of $40^{\circ} \mathrm{N}-25^{\circ} \mathrm{S}$ and $70^{\circ} \mathrm{W}-180^{\circ} \mathrm{W}$.

\subsubsection{Environmental Variables}

We evaluated whether satellite-derived measurement of SST, CHLA, zonal current (U), meridional current $(\mathrm{V})$, and sea surface height $(\mathrm{SSH})$ affected BUM and BLM distributions (Table 1). All spatial layers were acquired using the Marine 
Geospatial Ecology Tool (MGET) in ArcGIS, developed at Duke University (http://mgel.env.duke.edu/mget) (Hill et al. 2016). Due to differences in spatial resolutions, all spatial layers were resampled to a common spatial resolution $\left(0.1^{\circ}\right)$ to satisfy modelling requirements. Spatial layers with clusters of no-data cells, possibly due to cloud clover, were interpolated using the del2a method within MGET, which performs Laplacian interpolation and linear extrapolation. Depending on model criteria, environmental variables were averaged seasonally or climatologically.

\subsubsection{Habitat Modeling}

We used a SDM, maximum entropy model (MaxEnt), to estimate the probability distribution of BUM and BLM occurrence in the EPO. MaxEnt is a general-purpose machine learning method for making predictors or inferences from incomplete information (Phillips et al. 2006) making it appropriate for modeling species geographic distributions with presence-only data (Phillips et al. 2006). From a set of latitude and longitude coordinates, matched with a set of environmental variables from the same geographic area and time, we can determine the environmental factors that likely influence suitable habitat for these species. 60 simulations for each species with all possible combinations of the environmental variables were built.

We described the general seasonal suitable habitat of BUM and BLM in the EPO during 1997-2010 using seasonal climate. These simulations used three-month binned climatological averages of each environmental variable matched with each 
observation of the species during that period ( $\mathrm{n}=4$ for each species). Each threemonth bin represents a season: Fall (September - November), Winter (December February), Spring (March - May), and Summer (June - August). Additionally, El Niño-Southern Oscillation (ENSO) climate simulations were constructed to describe the general suitable habitat in each ENSO state: Niño Neutral, El Niño, and La Niña ( $\mathrm{n}=3$ for each species). Similar to the seasonal climate simulations, these simulations included climatological averages from environmental variables for each ENSO state matched with occurrences of the species. The ENSO states were determined by the Oceanic Niño Index (ONI) calculated by the NOAA NCEP Climate Prediction Center (http://origin.cpc.ncep.noaa.gov/products/analysis_monitoring/ensostuff/ONI_v5. php). ONI values for each ENSO state ranged from -0.4 to 0.4 for Niño Neutral, 0.5 to 2.3 for El Niño, and -0.5 to -1.7 for La Niña. Anomaly maps of habitat distribution were made relative to Niño Neutral distributions. Lastly, to capture the seasonal variability of suitable habitat each year from 1997-2010, "yearly" simulations included seasonal averages of the environmental variables and all the occurrences of the species during that period ( $\mathrm{n}=53$ for each species) in the EPO. All simulations were run using the freely available MaxEnt software, 3.4.1(http://biodiversityinformatics.amnh.org/open_source/maxent/). Model performance was evaluated with a five-fold cross-validation (500 iterations each), default regularization parameters, and a logistic output. To test model performance, $80 \%$ of the occurrence records were used to train the model and the remaining $20 \%$ were used for testing (Hill et al. 2016). All simulations produced an average output from 
the five-folds and response plots showing the predicted probability of presence as each environmental variable was varied. Lastly, a jackknife test of environmental variable importance (Hill et al. 2016) was applied to each model to determine the training gain of each variable if the model was run in isolation, and these were compared to the training gain with all the variables.

Model performance was evaluated using the area under the receiver operating characteristic curve (AUC). In presence-only modeling, the AUC represents the probability that the model fits better or worse than random occurrence (Phillips et al. 2006). An AUC value of 1 indicates a perfect fit of the data, a value of 0.5 indicates no better than random, and values approaching 0 means the model performed worse than random (Phillips et al. 2006).

To illustrate the effects of the factors on species distribution, the center of suitable habitat (CSH) for all simulations for each species was calculated using the mean_centre function in the R package "aspace" (Bui et al. 2012). This function computes the weighted mean center from a series of point locations (latitude and longitude) and suitability values from each model output. Preliminary analysis on CSHs revealed variability among seasons and potentially an ENSO influence on their distribution (Figure 2.2). As a result, we used an Analysis of Covariance (ANCOVA) (Whitlock and Schluter 2009) to test the effects seasonality (a factor) and strength of ENSO (ONI value) and the interaction between seasonality and ONI on CSH 1) latitude and 2) longitude. Separate ANCOVAs were run for both species. 


\subsection{Results}

All BUM and BLM simulations of suitable habitat produced AUC > 0.7 (Table 2), demonstrating that the MaxEnt model performs well for these highly mobile and broadly distributed species (Reside et al. 2011). BUM and BLM response plots to each environmental factor demonstrated variable results in all simulations (Figure 2.3 and 2.4). The most influential variable on BUM and BLM spatial distributions was CHLA, which had over $50 \%$ contribution in all simulations (Table 2). Overall, responses to CHLA show that BUM and BLM probability of occurrence was highest in waters with CHLA of $0.25 \mathrm{mg} / \mathrm{m}^{3}$ with a slight decline in waters with higher CHLA concentrations (Figure 2.3a and 2.4a). CHLA response plots show that BUM prefer areas with higher CHLA concentrations $\left(>2 \mathrm{mg} / \mathrm{m}^{3}\right)$ whereas BLMs' highest probability of occurrence was in waters with a CHLA between 0.25 and $2 \mathrm{mg} / \mathrm{m}^{3}$ (Figure 2.3a and 2.4a). This relationship with CHLA, however, breaks down at low SST (see discussion). Following CHLA, SST was the second most influential variable on BUM and BLM spatial distribution. SST contribution to BUM and BLM spatial distribution varied between $16 \%-30 \%$ (Table 2). For both species probability of occurrence rapidly increased as SST increased, but instead plateauing at high SSTs, declined rapidly when SSTs exceeded $26^{\circ} \mathrm{C}-28^{\circ} \mathrm{C}$. This indicates that both species prefer waters in the range of $23^{\circ} \mathrm{C}$ to $28^{\circ} \mathrm{C}$ (Figure $2.3 \mathrm{~b}$ and $2.4 \mathrm{~b}$ ). $\mathrm{SSH}$, an indicator of tides and ocean currents, ranked third in contribution to marlin spatial distribution, with peaks in spring and summer (Table 2). Although both species responded to change in SSH with declining probability of occurrence as SSH increased, BLM showed to have a 
stronger more uniform response compared to BUM in all simulations (Table 2, Figure $2.3 \mathrm{c}$ and 2.4c). Percent contributions by $\mathrm{U}$ and $\mathrm{V}$ were under $5 \%$ in all simulations and had negligible influences on the spatial distribution of both species (Table 2).

\subsubsection{Seasonal Variability}

Seasonal climate simulations demonstrated shifts in suitable habitat between coastal and oceanic waters in the EPO (Figure 2.5). In the winter and spring, suitable habitat for BUM and BLM was mostly in coastal waters of the EPO between $20^{\circ} \mathrm{N}$ and $20^{\circ} \mathrm{S}$ (Figure 2.5a, 2.5b, 2.5e, and 2.5f). Regions of high probabilities of occurrence were the Costa Rica Dome and the northern regions (Colombia, Ecuador, and Peru) of the Peru Current (Figure 2.5). In comparison to BLM, BUM's winter suitable habitat extended further offshore along the front of the equatorial cold tongue and began to narrow between $10^{\circ} \mathrm{N}$ and $10^{\circ} \mathrm{S}$ approaching the Central $\left(180^{\circ} \mathrm{W}\right)$ Pacific Ocean (CPO). Furthermore, the winter climate simulation showed suitable BUM habitat in the eastern Pacific warm pool; however, from spring to fall, this region became highly unsuitable for both species (Figure $2.5 \mathrm{~b}$ to $2.5 \mathrm{~h}$ ). In the spring, distribution of suitable habitat was more coastal with high probabilities of occurrence only extending as far out as $140^{\circ} \mathrm{W}$ and $120^{\circ} \mathrm{W}$ for BUM and BLM, respectively (Figure 2.5b and 2.5f). Variable contributions for the winter and spring climate simulations (Table 2) showed that the most influential variable on the spatial distributions for both species was CHLA followed by SST. 
In the summer and fall, suitable habitat shifted for both species to oceanic waters along the equator between $10^{\circ} \mathrm{N}$ and $10^{\circ} \mathrm{S}$ (Figure $2.5 \mathrm{c}, 2.5 \mathrm{~d}, 2.5 \mathrm{~g}$, and $2.5 \mathrm{~h}$ ). During these months, high suitability ran along the front of the equatorial cold tongue, extending out to $160^{\circ} \mathrm{W}$ in the waters of the North Equatorial Countercurrent (NECC) and the Southern Equatorial Current (SEC). Although the spatial distribution of suitable habitat shifted to waters offshore, the highest probabilities of occurrence were in waters off the coast of Colombia and Panama, south of the Costa Rica Dome. The variables with the highest percent of contributions to BUM and BLM spatial distributions in the summer and fall were CHLA followed by SST (Table 2).

\subsubsection{ENSO Variability}

Considerable variability was observed between the ENSO states (Niño neutral, El Niño, and La Niña) during 1997-2010 (Figure 2.6). Similar to the seasonal climate simulations, all three ENSO climate simulations predicted the eastern Pacific warm pool to be an unsuitable region. When the system was Niño Neutral, the extent of BUM and BLM suitable habitat ranged from the coasts of central and south America between $20^{\circ} \mathrm{N}$ and $20^{\circ} \mathrm{S}$ and narrowed toward the equator as it approaches the central Pacific (Figure 2.6a and 2.6d). Highly suitable regions were in and south of the Gulf of California, near the Costa Rica Dome, in the waters of the NECC and SEC adjacent to the equatorial cold tongue, and north of the Peru current. Latitudinal variability was also observed among the ENSO simulations. Both species moved to higher latitudes in the north EPO in conjunction with the strengthening of El Niño conditions (Figure 2.6b and 2.6e). These shifts to higher 
latitudes were seen most prominent when El Niño's were “strong” such as in the Fall of 1997 (Figure 2.7b and 2.7e). The suitable habitat of BUM and BLM moved northward, between $10^{\circ} \mathrm{N}$ and $20^{\circ} \mathrm{N}$, into the waters of the North Equatorial current. In contrast, during a La Niña state BUM and BLM experienced a range reduction in suitable habitat between $10^{\circ} \mathrm{N}$ and $10^{\circ} \mathrm{S}$ and the waters of the SEC and Peru current become unsuitable (Figure 2.6c and 2.6f). This shift to lower latitudes is again more pronounced during a "strong" La Niña (Figure 2.7c and 2.7f). During La Niña periods the waters of the NECC along the equatorial front are a highly suitable region for both species.

In all ENSO climate simulations, the variable with the highest percent of contribution was CHLA, which ranged from $67.1 \%$ to $77.1 \%$ and $61.4 \%$ to $68.3 \%$ for BUM and BLM, respectively (Table 2). Response plots from these simulations displayed low variability in results for both species (Figure 2.3 and 2.4). In all three ENSO states, BUM and BLM preferred to inhabit the waters with CHLA concentrations above $0.25 \mathrm{mg} / \mathrm{m}^{3}$, SST between $23^{\circ} \mathrm{C}$ and $28^{\circ} \mathrm{C}$, and SSH below $0.8 \mathrm{~m}$ (Figure 2.3a, 2.3b, 2.4a, and 2.4b).

\subsubsection{Center of Suitable Habitat (CSH)}

ANCOVA analysis on the effects season and ENSO had on the latitudinal and longitudinal position of the center of suitable habitat $(\mathrm{CSH})$ varied between BUM and BLM (Figure 2.8 and Table 3). Analogous to trends from seasonal climate simulations, ANCOVA results showed a longitudinal seasonal shift in suitable habitat in the EPO (Figure 2.2). The BUM CSH significantly differed 
between the spring and fall months, occupying waters eastward in the spring and waters farther west in the fall (Figure 2.8 and Table 3). Winter and summer did not differ from one another but rather with fall and spring (Table 3). Trend lines showed that during these seasons the BUM CSH's longitudinal position was most likely between $115^{\circ} \mathrm{W}-119^{\circ} \mathrm{W}$, which falls within the spring and fall extremes (Figure 2.8) suggesting that winter and summer act as the transitional phases as the BUM CSH shift from the coastal to oceanic waters. BLM did not exhibit this transitional phase. Spring and winter CSH were in more eastward waters and significantly differed from the fall and summer when the BLM CSH shifts to waters farther west (Figure 2.8 and Table 3). Additionally, the strength of ENSO events significantly affected the longitudinal distribution for both species (Table 3) by shifting their distribution closer to the coast as the strength of El Niño increased (high ONI values) and further offshore as strength of La Niña increased (low ONI values) (Figure 2.8).

Furthermore, latitudinal CSH distributions differed between BUM and BLM (Figure 2.8 and Table 3). ANCOVA results revealed that the BUM latitudinal positions were significantly different among all seasons (Table 3). Similar with the longitudinal results, the fall and spring appeared to act as two extremes, with CSH distributed in the most northern latitudes, above $2^{\circ} \mathrm{N}$, in the fall and in the most southern latitudes, potentially crossing the equator, in the spring (Figure 2.8). Although these results indicated that summer and winter statistically differed from one another (Table 3), in both seasons' CSH latitudinal positions fell between spring and fall, suggesting that these seasons are transitional phases (Figure 2.8). 
Again, these transitional phases were not exhibited by BLM, but rather BLM in the fall and summer inhabited higher latitudes, between $2^{\circ} \mathrm{N}-4^{\circ} \mathrm{N}$ and occupied low latitudes, between $2^{\circ} \mathrm{N}-1^{\circ} \mathrm{S}$ in the winter and spring (Figure 2.8). Lastly, there was no significant relationship between the strength of ENSO and latitudinal position of either BUM or BLM CSHs (Table 3).

\subsection{Discussion}

Incidental catch data from EPO tuna purse-seine fisheries, remotely-sensed environmental data, and MaxEnt model simulations provided a unique opportunity to identify the habitat preferences and spatial distributions of BUM and BLM and to observe the effects of variability in environmental conditions. Our results demonstrated that high CHLA concentrations $\left(>0.25 \mathrm{mg} / \mathrm{m}^{3}\right)$ and warm SST (23$28^{\circ} \mathrm{C}$ ) waters are the primary drivers in the spatial distribution of suitable habitats for both BUM and BLM. Our results are consistent with previous studies (Graves et al. 2002, Boyce et al. 2008, Su et al. 2008, Su et al. 2011, Chiang et al. 2015, Hill et al. 2016, Carlisle et al. 2017) in finding seasonal and ENSO variability in spatial distribution of BUM and BLM in the Pacific Ocean.

\subsubsection{Influence of environmental factors}

Several previous studies found in general that SST or DO were the most influential variables on the distribution for both species, and that CHLA did not affect distributions of habitats (Holland et al. 1990, Graves et al. 2002, Prince and Goodyear 2006, Su et al. 2008, Chiang et al. 2015, Carlisle et al. 2017). However, due to the resolution of the data used in these studies, the power to identify an effect 
of CHLA on BUM and BLM distributions was likely low. These studies obtained data principally from BUM and BLM in oceanic waters where CHLA is less variable than in more coastal and highly productive environments. In contrast, the tuna purse-seine fishery obtains data from both nearshore and oceanic waters. Therefore, the BUM and BLM bycatch from this fishery was likely to be representative of their distributions in the entire EPO, which allowed us to contextualize previous results. All our simulations indicated that CHLA was the most influential factor determining BUM and BLM spatial distributions (Table 2). Our results suggests that both species choose to inhabit in highly productive waters in the EPO. Brill and Lutcavage (2001) observed that CHLA may be an indirect surrogate measure of forage abundance for large pelagic fishes. From our simulations, both species exhibited shifts in spatial distribution in relation to shifts in upwelling. For example, BUM and BLM simulations predicted high suitability in the north Peru Current, Costa Rica Dome, and southern portion of the California Current during the boreal winter and spring when the trade winds intensify and create favorable upwelling conditions in the coastal waters (Amador et al. 2006, Pennington et al. 2006). However, suitability values were rather low in the eastern Pacific warm pool during these seasons as the waters in this region are nutrient poor due to high stratification (Pennington et al. 2006). Additionally, BUM and BLM relationship with CHLA breaks down in high CHLA, low SST waters. For example, waters off California and northwest Mexico, in the California Current, are highly productive due to coastal upwelling (Pennington et al. 2006), however, these waters are too cold $\left(15^{\circ} \mathrm{C}-20^{\circ} \mathrm{C}\right)$ (Huyer 1983) for BUM and BLM preference. 
BUM and BLM prefer warm tropical waters $\left(23^{\circ} \mathrm{C}-28^{\circ} \mathrm{C}\right)($ Figure $2.3 \mathrm{~b}$ and 2.4b). These results were consistent with tagging studies that documented BUM and BLM seasonal migrations between higher latitudes in the summer and lower latitudes in the winter (Howard and Ueyanagi 1965, Su et al. 2008, Chiang et al. 2015, Carlisle et al. 2017). Due to their preferences for warm SST, both species have been observed to exhibit seasonal migrations, which may be related to spawning and foraging (Howard and Ueyanagi 1965, Shimose et al. 2006, Shimose et al. 2008, Domeier and Speare 2012, Shimose et al. 2012). In the northern waters $\left(10^{\circ} \mathrm{N}-30^{\circ} \mathrm{N}\right)$ of the western Pacific Ocean (WPO) BUM are usually in high densities from May through October (Howard and Ueyanagi 1965). Additionally, in this region female BUM undertake large foraging movements north after spawning and move to more productive waters to feed (Shimose et al. 2012). By contrast, the south/southeastern waters (south of $10^{\circ} \mathrm{S}$ ) of the EPO generally have higher densities of BUM from November through March, with fish often moving across the equator, between $160^{\circ} \mathrm{E}-170^{\circ} \mathrm{W}$, towards French Polynesia (Howard and Ueyanagi 1965). This northwest - southeast migration in the Pacific Ocean is considered to indicate shifts of their habitats in accordance with the seasonal change of rising sea surface temperatures progressing from west to east, and also is thought to be related to spawning (Howard and Ueyanagi 1965). This movement is consistent with our results, as BUM CSH was observed to be in its most southeasterly position during spring (Figure 2.8). Currently, the only known spawning regions for BLM are in the WPO in the waters of the Coral Sea and the south China Sea. Therefore, seasonal migrations for BLM in the EPO may be 
related to foraging, considering we observed that CHLA is the most influential factor affecting their distribution.

\subsubsection{Seasonal Distribution Patterns}

Our findings of the BUM and BLM seasonal shifts in distribution (Figure 2.5) were similar to those in Acosta-Pachón et al. (2017) on the habitat preferences of striped marlin, Kajikia audax, in the EPO. Using SDM they found that the most suitable habitat for striped marlin was highly productive warm waters of the EPO and that striped marlin distributions shifted seasonally between coastal waters in the boreal winter and oceanic waters in the boreal summer. The Inter-Tropical Convergence Zone (ITCZ) reaches its southernmost position, $5.3^{\circ} \mathrm{S}$, during the boreal winter and much of the spring (Donohoe et al. 2013). During this time, the northeasterly trade winds intensify and the Tehuantepec, Papagayo, and Panama jets strengthen (Amador et al. 2006). As a result, surface waters are advected westward, allowing deep nutrient-rich waters to be upwelled to the surface, particularly in more coastal regions, such as the Costa Rica Dome. BUM and BLM preference for these productive waters was consistent with our ANCOVA analysis that showed CSH to be more eastward in the boreal winter and spring (Figure 2.2 and 2.8). In the late fall and throughout the winter, Tehuantepec and Papagayo jets also produce both cyclonic and anticyclonic eddies in the region off Guatemala (Willett et al. 2006). These eddies are known to significantly affect the distribution of highly migratory species (Seki et al. 2002, Kobayashi et al. 2008, Godø et al. 2012, Woodworth et al. 2012). The eddies are a retention mechanism for planktonic organisms, eggs, and larvae, which are sources of food for first-order consumers in 
the food chain (Ehrhardt and Fitchett 2006). As these eddies drift into the central Pacific Ocean (CPO), BUM and BLM suitable habitat extends within them.

Preferred habitat was found in the northern regions of the Peru Current in the winter and spring (Figure 2.5b and 2.5f). This region experiences strong seasonal upwelling with its highest levels of CHLA and primary production occurring in the boreal winter (Kessler 2006, Pennington et al. 2006). In addition, drifting warm water from the equator may rest above upwelled cool waters, forming ideal conditions for BUM and BLM (Acosta-Pachón et al. 2017).

In the boreal summer and fall months, the ITCZ shifts to the northern latitudes, $7.2^{\circ} \mathrm{N}$, weakening the upwelling winds and eddies that peak in the boreal winter and spring in the EPO (Pennington et al. 2006, Donohoe et al. 2013). As a result, waters that were favorable for BUM and BLM in the winter and spring (Costa Rica Dome, northern Peru Current, southern California Current) became unsuitable for both species. BUM and BLM distributions shift to the open ocean along the front of the equatorial cold tongue (Figure $2.5 \mathrm{c}, 2.5 \mathrm{~d}, 2.5 \mathrm{~g}$, and $2.5 \mathrm{~h}$ ). In contrast to winter and spring, summer and fall CSHs shift offshore to more oceanic waters (Figure 2.8). The cold tongue, a highly productive open oceanic upwelling region between the equator and $10^{\circ} \mathrm{N}$, experiences moderate seasonal variability. Its coldest and most productive period is September, when upwelling is strongest (Pennington et al. 2006). In the summer and fall, phytoplankton and zooplankton biomass are maximal (Fernández-Álamo and Färber-Lorda 2006, Pennington et al. 2006). This biomass attracts smaller fish and thus creates areas with high prey concentration for BUM and BLM. The BUM and BLM distribution along the cold 
tongue are consistent with the Olson et al. (1994)'s finding that billfish tend to aggregate along oceanic fronts (such as temperature fronts), that may be areas of increased productivity and relatively high prey abundance. BUM and BLM were observed diving into deep, colder waters during the day to forage (Holland et al. 1990, Block et al. 1992, Goodyear et al. 2008, Chiang et al. 2015). BUM and BLM cranial endothermy, counter-current heat exchangers and thermogenic tissue, allow for heat to be generated and retained in the brain and eye regions (Fritsches et al. 2003). This allows for better visual acuity in cold, deep waters while diving, which may be used for similar purposes if they forage in the cold surface waters of the equatorial cold tongue.

\subsubsection{ENSO's Impact on Distribution Patterns}

The unique oceanography of the EPO is heavily influenced by ENSO, which is arguably the most significant source of temporal variability in the tropical waters of the EPO (Pennington et al. 2006). The El Niño events are triggered by weakening or reversal of the coastal trade winds in the western Pacific in response

to the atmospheric pressure change across the Pacific Ocean. As a result, the physical effects of El Niño involve weakening of the north equatorial current and south equatorial current, deepening of the thermocline and nutricline, thus suppressing primary production (Pennington et al. 2006). During El Niño, diminished primary production and the deepened thermocline have detrimental effects on the survival and reproduction, and affect the distribution of higher trophic level organisms (Ballance et al. 2006). Based on our El Niño anomaly map (Figure 2.6b and 2.6e), BUM and BLM habitat suitability diminished among equatorial and 
coastal upwelling areas during El Niño. Although upwelling continues in the cold tongue, the Costa Rica Dome, and off Peru, the upwelled waters come from the warm and nutrient-poor upper layer (Pennington et al. 2006), which consistently diminish the productivity in these areas. As the westward-moving North and South Equatorial Current weaken or reverse during an El Niño, the north equatorial counter-current strengthens and advects warm waters of the west Central Pacific into the EPO (Kessler 2006). Therefore, the EPO currents normally just north of the equator move northward to $8-10^{\circ} \mathrm{N}$ and those starting around $8-10^{\circ} \mathrm{N}$ move to the east-northeast (Hinton 2015). In the southern hemisphere the currents show similar patterns, but in the west-southwest direction (Hinton 2015). This likely explains why BUM and BLM suitable habitats branched off into $10-15^{\circ} \mathrm{N}$ and $10-$ $15^{\circ} \mathrm{S}$ waters during El Niño (Figure 2.6b, 2.6e, 2.7b, and 2.7e). Currently, it is unknown what effect these current anomalies have on primary production, but it does advect warm waters to higher latitudes where these waters may normally be too cold for BUM or BLM.

The La Niña anomaly maps show that the BUM and BLM habitat suitability increas along the equator and extends westward during a La Niña (Figure 2.6c and 2.6f). La Niña events are associated with a strengthened westward flow of the Southern Equatorial Current which leads to increased equatorial upwelling, shoaling of the thermocline and nutricline, and an overall extension of the equatorial cold tongue from the Eastern Pacific into the Central Pacific (Pennington et al. 2006, Carlisle et al. 2017). Therefore, these productive cold waters create oceanic fronts extending westward in which marlins aggregate (Olson et al. 1994). 
Carlisle et al. (2017) observed blue marlin, tagged with pop-up archival transmitting tags, to have a close proximity to this westward extension of the cold tongue. However, the cold tongue appears to act as a barrier that they do not cross.

From the 14 years of occurrence data, we were able to capture the effects of each El Niño and La Niña on BUM and BLM spatial distributions. Our findings suggest that the strength of and ENSO event significantly influences marlin presence as it displaces their suitable habitat. ANCOVA analysis on CSH (Figure 2.8) showed that higher ONI values (strong El Niño) push BUM and BLM distributions closer to coastal waters. For example, in Fall of 1997, during a strong El Niño, BUM CSH was 985 km east relative to Nino-neutral conditions (Figure 2.2). Similarly, Su et al. (2011) observed that the BUM population moved east during the 1997-1998 El Niño. By contrast, negative ONI values (strong La Niña) displaced BUM and BLM further offshore. Although, our simulations of BUM and BLM suitable habitat during an El Niño (La Niña) showed they moved to higher (lower) latitudes, there was not a statistically significant effect of ENSO strength on CSH latitudinal position. These anomalies of the distribution of suitable habitat of BUM and BLM during different ENSO states may have important implications for the population dynamics and migration behavior of these species, especially if it hinders important feeding or reproductive migrations (Carlisle et al. 2017). 
Table 2.1 Environmental variables used as covariates in the MaxEnt model. 


\begin{tabular}{|c|c|c|c|c|c|}
\hline $\begin{array}{l}\text { Environmental } \\
\text { variable }\end{array}$ & Product & $\begin{array}{c}\text { Spatial } \\
\text { resolution }\end{array}$ & $\begin{array}{l}\text { Temporal } \\
\text { resolution }\end{array}$ & Unit & Source \\
\hline $\begin{array}{l}\text { Chlorophyll-a } \\
\text { Concentration } \\
\text { (CHLA) }\end{array}$ & $\begin{array}{l}\text { SeaWIFS } \\
\text { L3 }\end{array}$ & $.1^{\circ}$ & Monthly & $\mathrm{mg} / \mathrm{m}^{3}$ & https://oceandata.sci.gsfc.nasa.gov/SeaWiFS/L3SMI/ \\
\hline $\begin{array}{l}\text { Sea surface } \\
\text { temperature } \\
\text { (SST) }\end{array}$ & $\begin{array}{l}\text { GHRSST } \\
\text { L4 } \\
\text { AVHRR, } \\
\text { Optimum } \\
\text { Interpolation } \\
\text { (Elith et al.), } \\
\text { Global }\end{array}$ & $.25^{\circ}$ & Daily & ${ }^{\circ} \mathrm{C}$ & $\begin{array}{l}\text { https://podaac.jpl.nasa.gov/dataset/AVHRR_OI-NCEI-L4- } \\
\text { GLOB-v2.0 }\end{array}$ \\
\hline $\begin{array}{l}\text { Sea Surface } \\
\text { Height (SSH) }\end{array}$ & $\begin{array}{l}\text { AVISO } \\
\text { Absolute } \\
\text { Dynamic } \\
\text { Topography } \\
\text { (MADT-H), } \\
\text { DT all sat, } \\
\text { Global }\end{array}$ & $.1^{\circ}$ & Daily & $\mathrm{m}$ & https://www.aviso.altimetry.fr/index.php?id=1271 \\
\hline Zonal current (U) & $\begin{array}{l}\text { NOAA } \\
\text { Ocean } \\
\text { Surface } \\
\text { Current } \\
\text { Analyses - } \\
\text { Real Time } \\
\text { (Hobday, } \\
\text { Hartog, } \\
\text { Spillman, \& } \\
\text { Alves) } \\
\end{array}$ & $.33^{\circ}$ & $5-d$ & $\mathrm{~m} / \mathrm{s}$ & $\begin{array}{l}\text { https://podaac.jpl.nasa.gov/dataset/OSCAR_L4_OC_third- } \\
\text { deg }\end{array}$ \\
\hline $\begin{array}{l}\text { Meridional } \\
\text { current }(\mathrm{V})\end{array}$ & $\begin{array}{l}\text { NOAA } \\
\text { Ocean } \\
\text { Surface } \\
\text { Current } \\
\text { Analyses - } \\
\text { Real Time } \\
\text { (Hobday et } \\
\text { al.) }\end{array}$ & $.33^{\circ}$ & 5-d & $\mathrm{m} / \mathrm{s}$ & $\begin{array}{l}\text { https://podaac.jpl.nasa.gov/dataset/OSCAR_L4_OC_third- } \\
\text { deg }\end{array}$ \\
\hline
\end{tabular}


Table 2.2 Variable contributions (\%) and area under curve (AUC) of the seasonal and El Niño-Southern Oscillation (ENSO) climate simulation for blue marlin (BUM) and black marlin (BLM). The variables that contribute the most to each simulation are highlighted in bold. 


\begin{tabular}{|c|c|c|c|c|c|c|c|c|}
\hline Species & AUC/Variable & Winter & Spring & Summer & Fall & $\begin{array}{c}\text { Niño } \\
\text { Neutral }\end{array}$ & El Niño & La Niña \\
\hline \multirow{6}{*}{$\frac{\sum}{\infty}$} & $\mathrm{AUC}$ & 0.783 & 0.791 & 0.821 & 0.817 & 0.745 & 0.774 & 0.790 \\
\hline & $\begin{array}{l}\text { Chlorophyll-a } \\
\text { Concentration } \\
\text { (CHLA) }\end{array}$ & 63.8 & 62.1 & 65.3 & 61.1 & 77.1 & 67.1 & 70.9 \\
\hline & $\begin{array}{l}\text { Sea surface } \\
\text { temperature (SST) }\end{array}$ & 28.8 & 21.8 & 18.5 & 29.9 & 16.6 & 23.6 & 20.4 \\
\hline & $\begin{array}{l}\text { Sea Surface Height } \\
\text { (SSH) }\end{array}$ & 3.7 & 14.7 & 14.7 & 5.9 & 5.7 & 8.6 & 7.6 \\
\hline & Zonal current (U) & 1.5 & 0.9 & 1.4 & 2.7 & 0.5 & 0.7 & 0.9 \\
\hline & Meridional (V) & 2.2 & 0.6 & 0.1 & 0.5 & 0 & 0.1 & 0.2 \\
\hline \multirow{6}{*}{$\frac{\sum}{\infty}$} & AUC & 0.823 & 0.835 & 0.848 & 0.841 & 0.785 & 0.811 & 0.832 \\
\hline & $\begin{array}{l}\text { Chlorophyll-a } \\
\text { Concentration } \\
\text { (CHLA) }\end{array}$ & 57 & 56.1 & 57.5 & 58 & 68.3 & 61.4 & 63 \\
\hline & $\begin{array}{l}\text { Sea surface } \\
\text { temperature (SST) }\end{array}$ & 26.2 & 21.6 & 19.2 & 24 & 16.2 & 22.6 & 19 \\
\hline & $\begin{array}{l}\text { Sea Surface Height } \\
\text { (SSH) }\end{array}$ & 12.7 & 21.9 & 19.6 & 13.9 & 14.8 & 15.1 & 16.1 \\
\hline & Zonal current (U) & 1.4 & 0.5 & 3.5 & 3.7 & 0.6 & 0.7 & 1.9 \\
\hline & Meridional (V) & 2.7 & 0.3 & 0.2 & 0.4 & 0.1 & 0.2 & 0 \\
\hline
\end{tabular}


Table 2.3 Analysis of Covariance on the effect seasonality and strength of El NiñoSouthern Oscillation (ENSO) and the interaction between seasonality and ENSO on center of suitable habitat 1) latitude and 2) longitude. Oceanic Niño Index (ONI) values were utilized to represent strength of ENSO. A * denotes significance at $\mathrm{p}<0.10, * * \mathrm{p}<0.05, * * * \mathrm{p}<0.01, * * * * \mathrm{p}<0.001$. 


\begin{tabular}{|c|c|c|c|c|c|c|}
\hline Black & irlin & & Blue & & In & \\
\hline 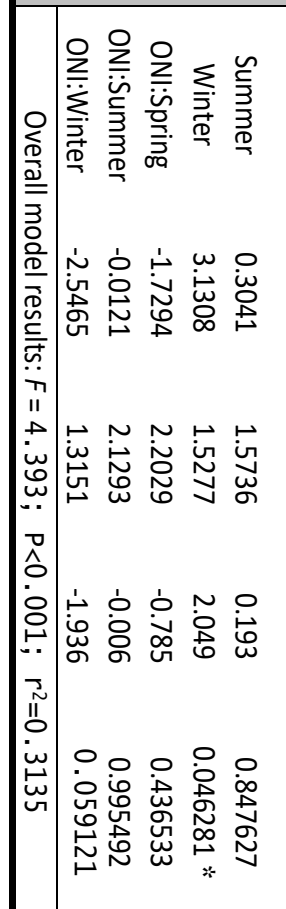 & 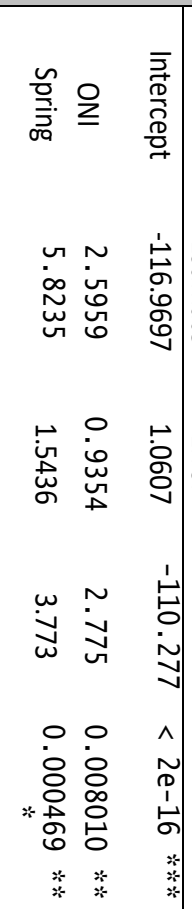 & 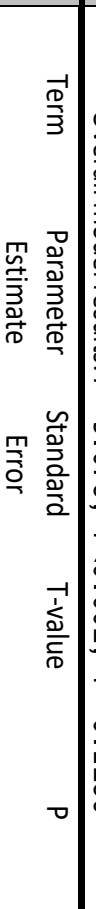 & 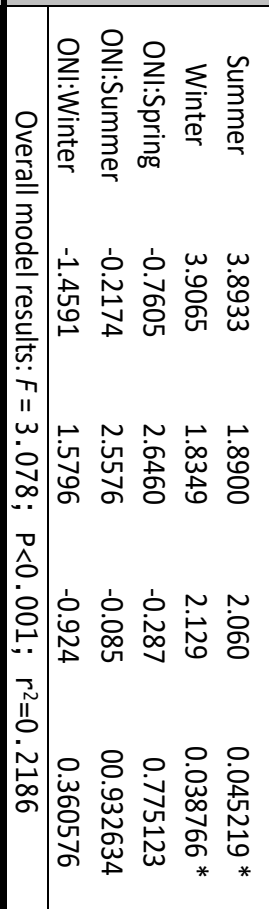 & 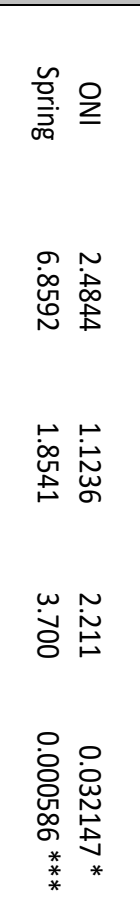 & 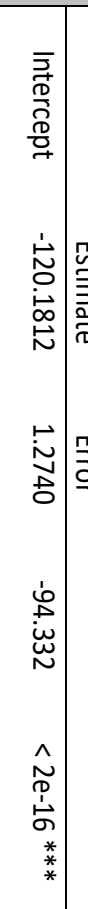 & 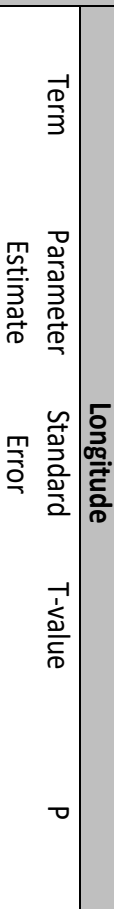 \\
\hline 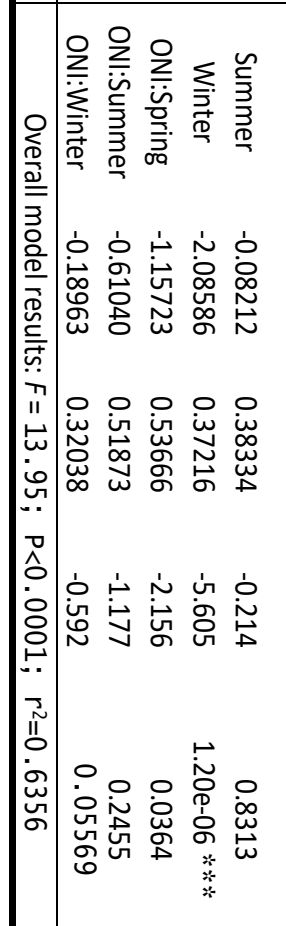 & 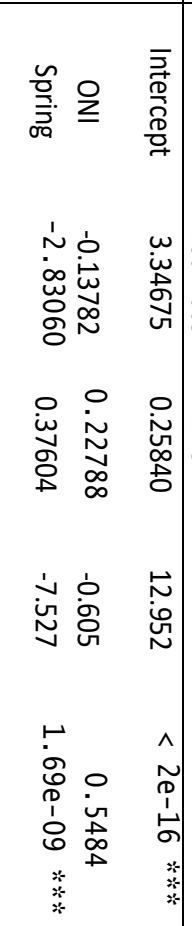 & 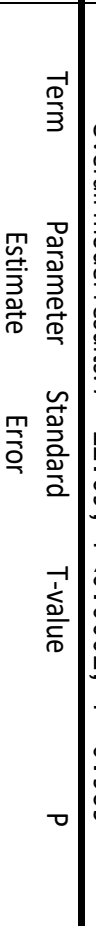 & 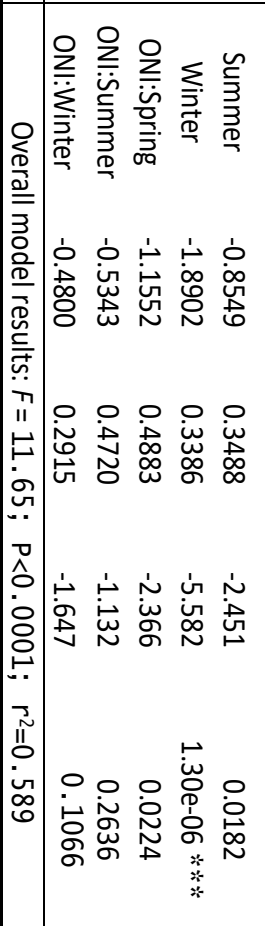 & 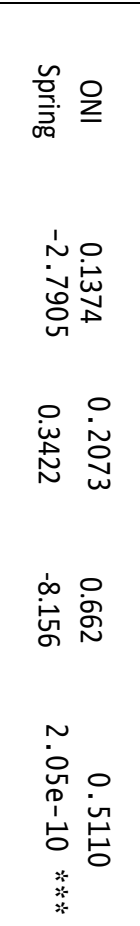 & 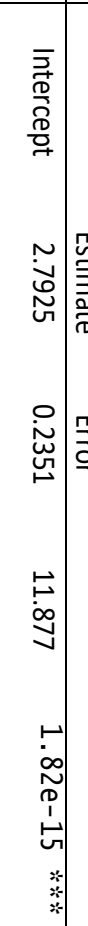 & 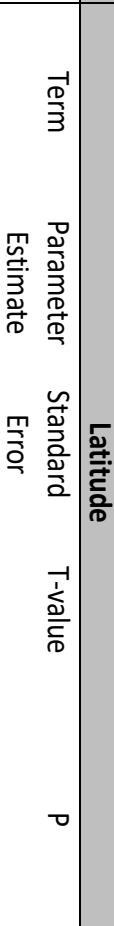 \\
\hline
\end{tabular}


Figure 2.1 (a) Spatial distribution of fishing effort of the tuna purse-seine fishery, and density plots of (b) the distribution of blue marlin (BUM) and (c) black marlin (BLM) occurrence records in the EPO during 1997-2010. Color Scale represents. 

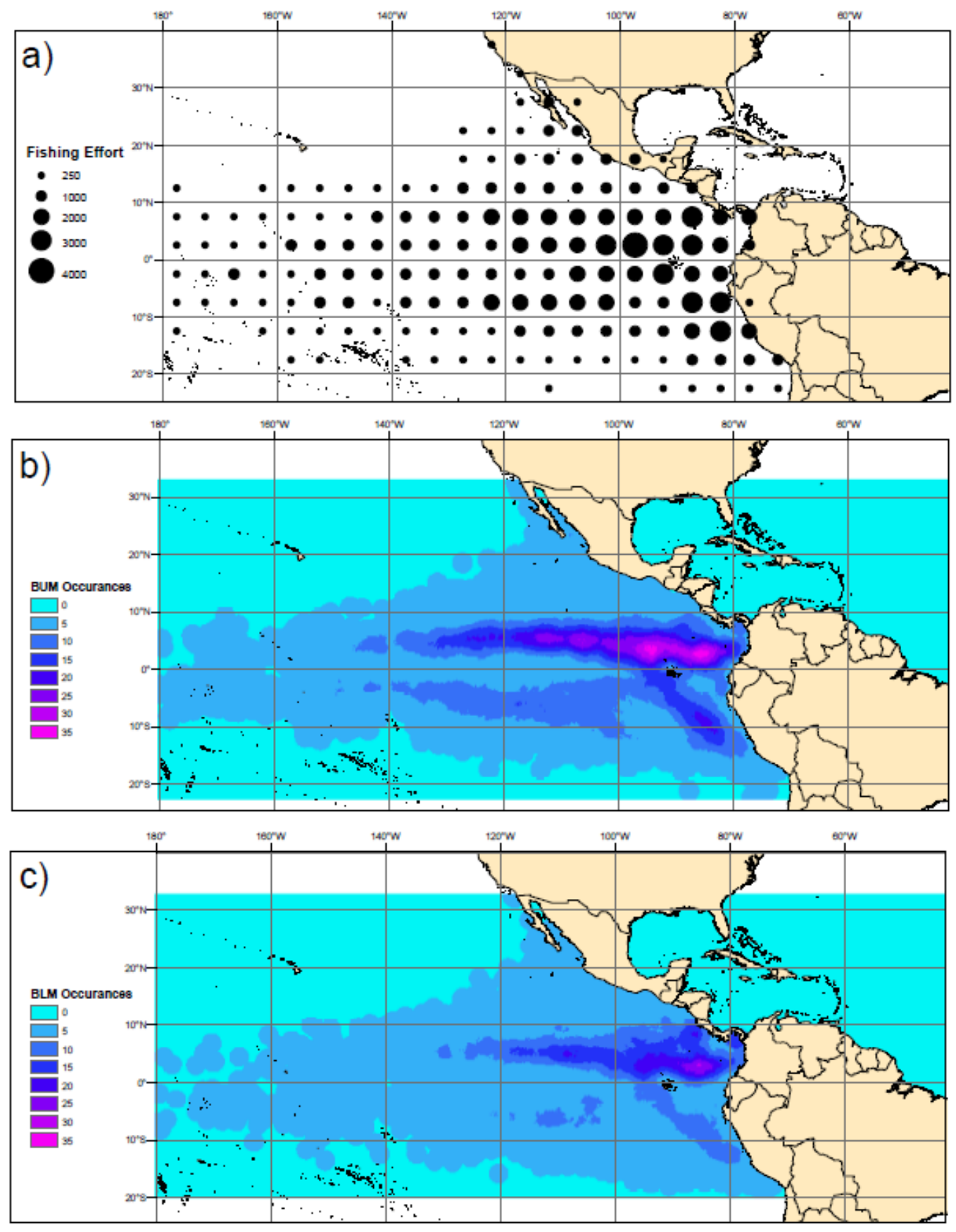
Figure 2.2 Seasonal distribution of center of suitable habitat (CSH) for BUM and BLM in the EPO from 1997-2010 predicted by the yearly MaxEnt simulations. CSH marked with symbols represent seasons when either a "strong" El Niño or La Niña largely displaced BUM or BLM suitable habitat. 


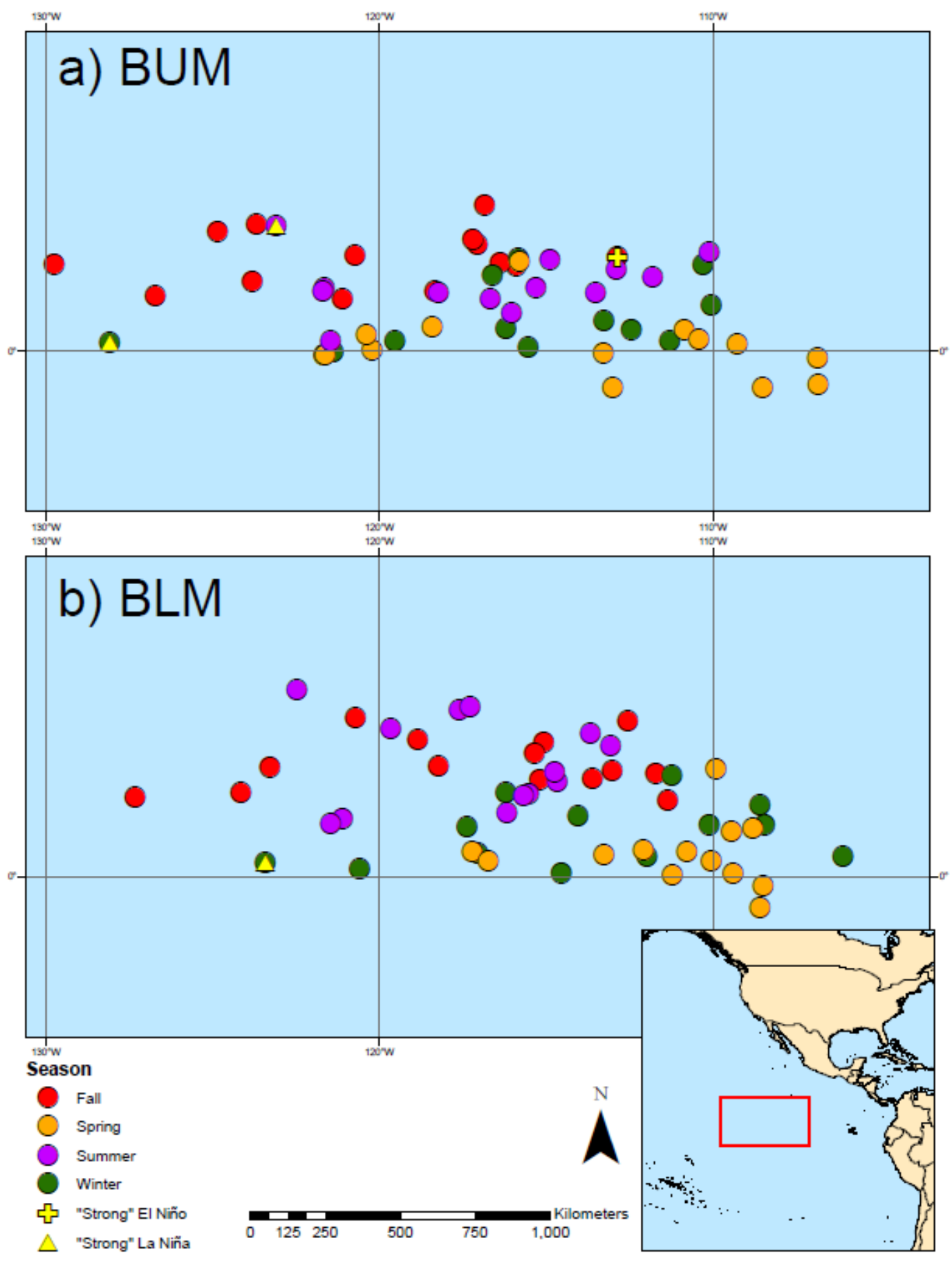


Figure 2.3 Probability of presence of blue marlin as a response to (a) chlorophyll a (CHLA), (b) sea surface temperature (SST), (c) sea surface height (SSH), (d) Zonal current (U), (e) meridional current (V) in the eastern Pacific Ocean under each season (Winter, Spring, Summer, Fall) and Niño condition (El Niño, La Niña, Niñoneutral). 

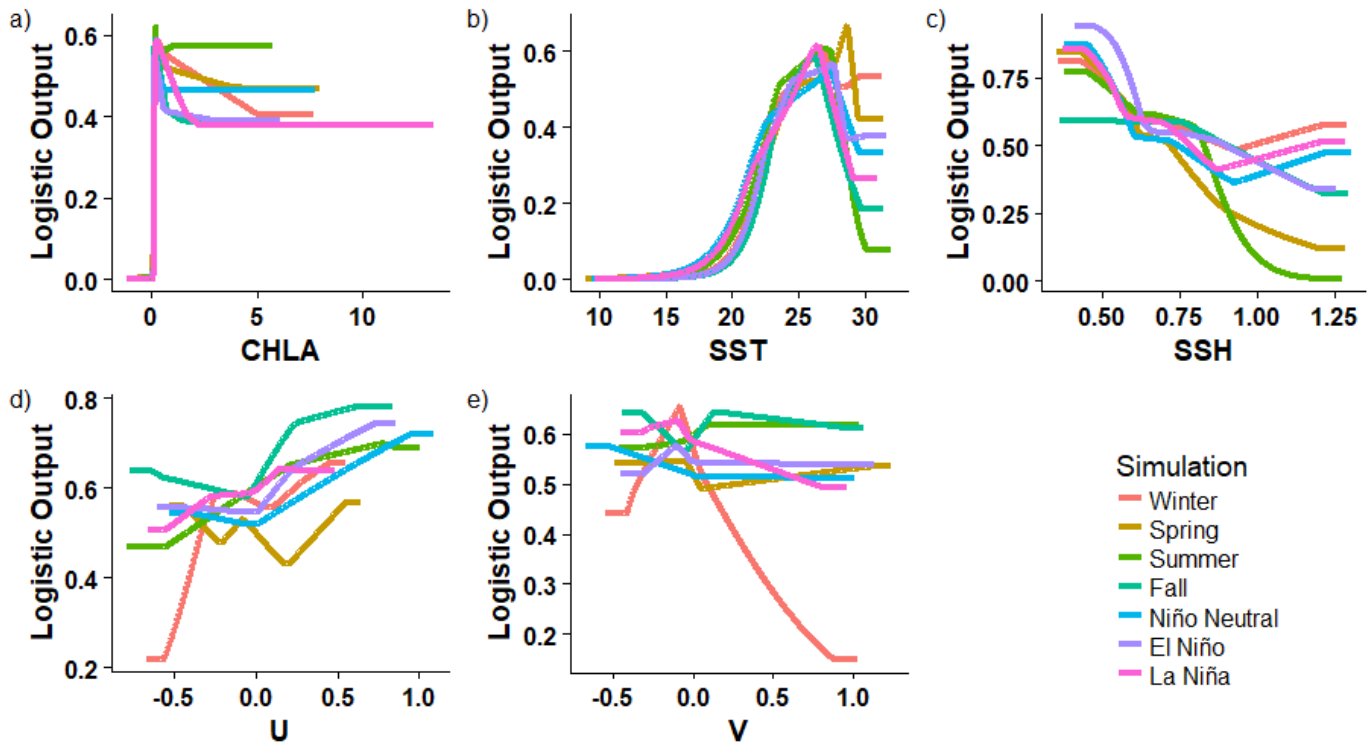

Simulation

- Winter

- Spring

- Summer

- Fall

- Niño Neutral

- El Niño

- La Niña 
Figure 2.4 Probability of presence of black marlin as a response to (a) chlorophyll $a$ (CHLA), (b) sea surface temperature (SST), (c) sea surface height (SSH), (d) Zonal current (U), (e) meridional current (V) in the eastern Pacific Ocean under each season (Winter, Spring, Summer, Fall) and Niño condition (El Niño, La Niña, Niño-neutral). 

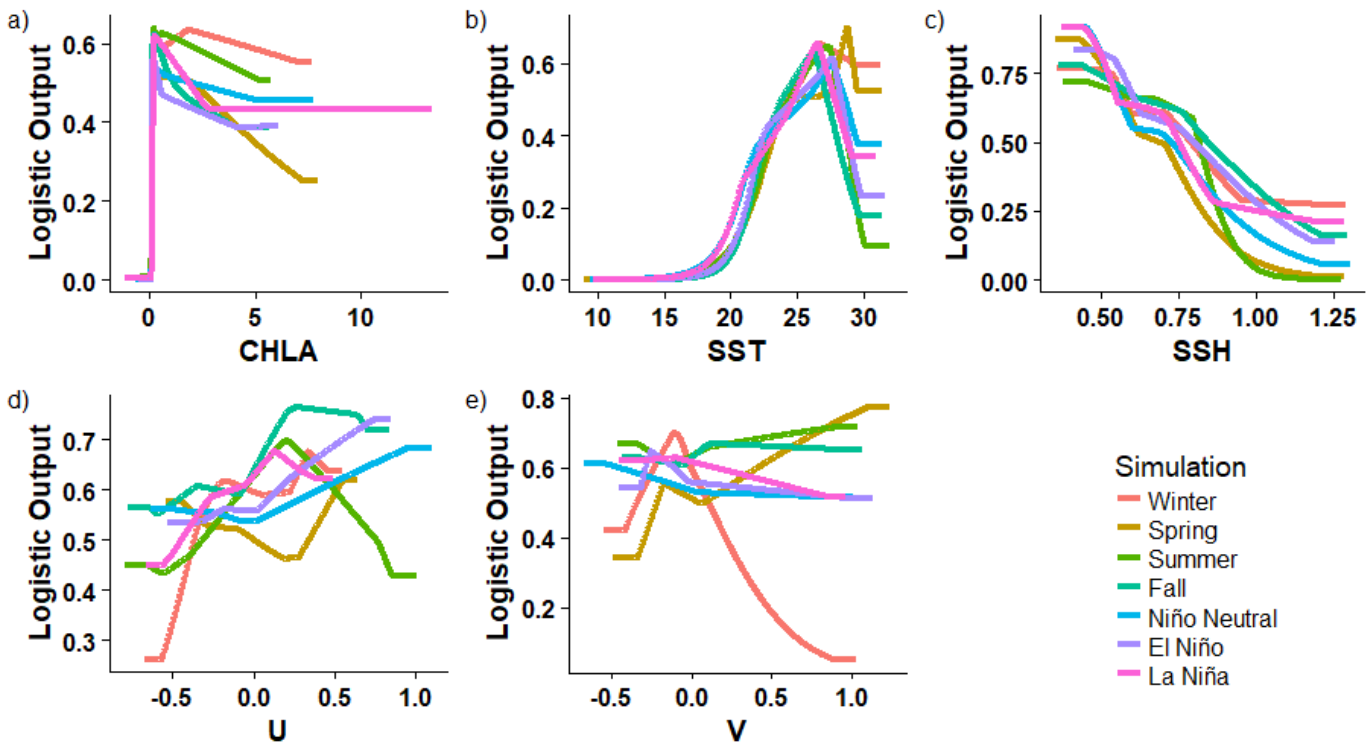

Simulation

- Winter

- Spring

- Summer

- Fall

- Niño Neutral

- El Niño

- La Niña 
Figure 2.5 Seasonal distribution ((a,e) Winter, (b,f) Spring, (c,g) Summer, (d,h) Fall) of habitat suitability for blue marlin (BUM) and black marlin (BLM) in the eastern Pacific Ocean (EPO) predicted by the seasonal climate MaxEnt simulations. Color scale represents the probability of BUM and BLM presence. 
BUM
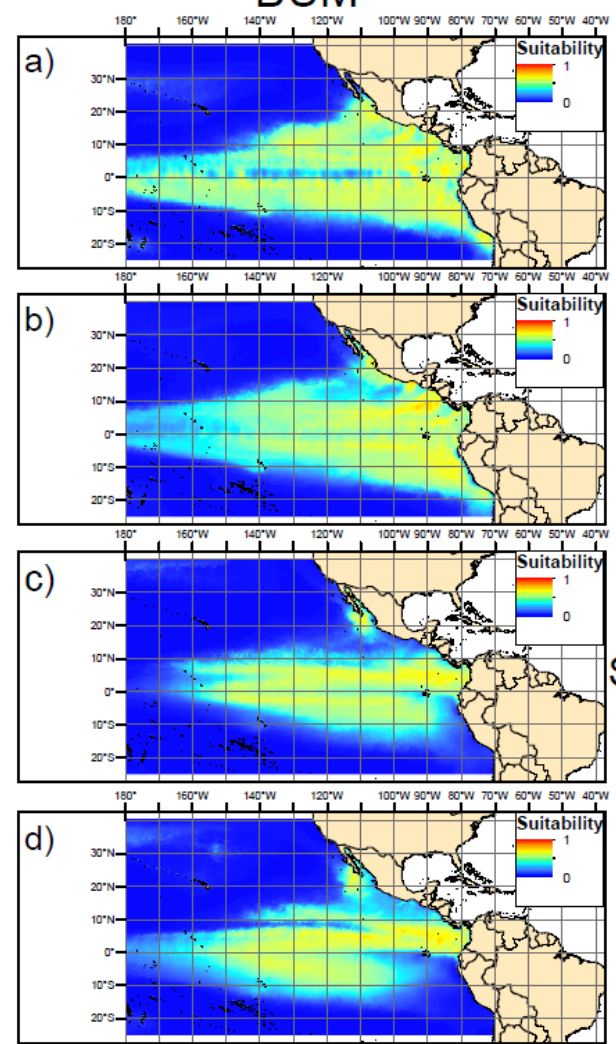

BLM

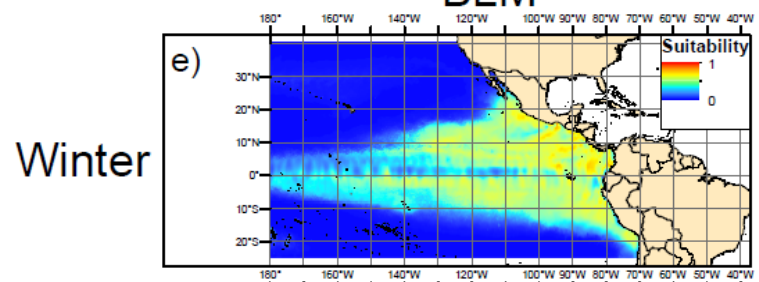

Spring
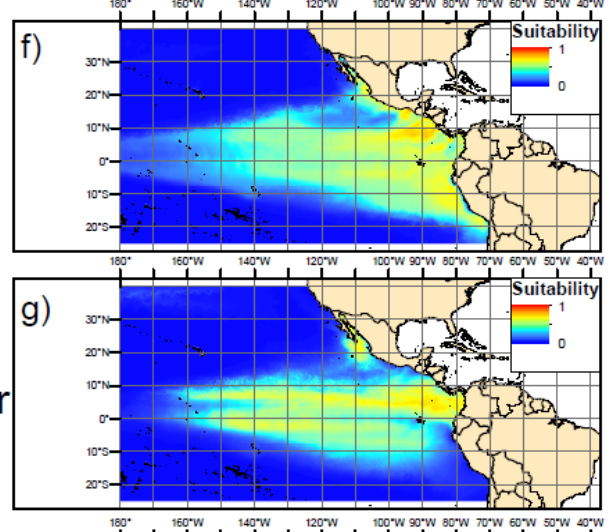

Fall

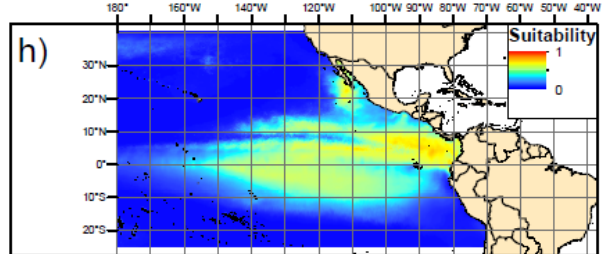


Figure 2.6 El Niño-Southern Oscillation (ENSO) distribution of habitat suitability for blue marlin (BUM) and black marlin (BLM) in the eastern Pacific Ocean (EPO) predicted by the ENSO climate MaxEnt simulations. Color scale represents the probability of presence of BUM and BLM $(a, d)$ Niño Neutral $(b, e)$ El Niño anomaly from Niño Neutral $(c, f)$ La Niña anomaly from Niño Neutral. 

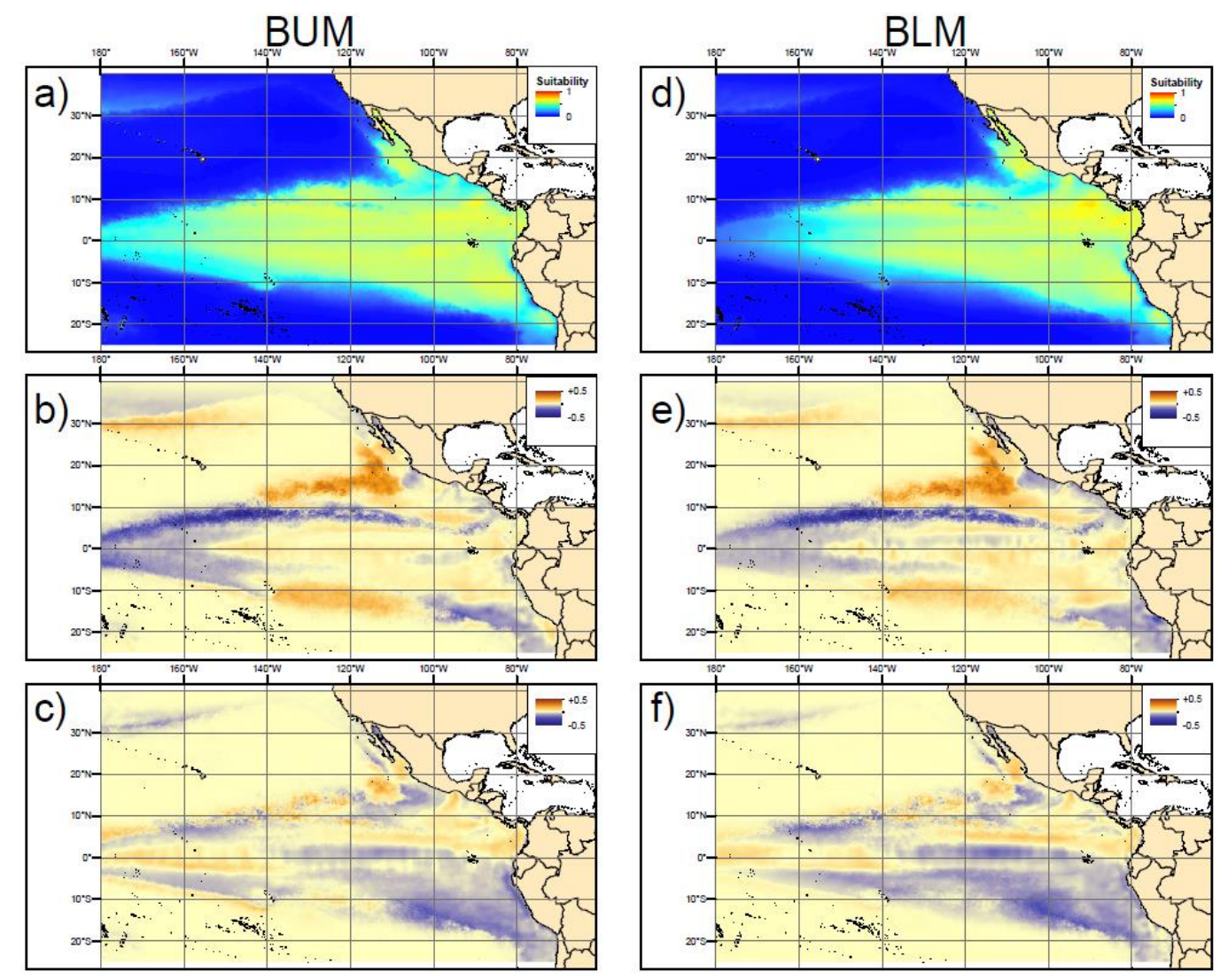
Figure 2.7 El Niño-Southern Oscillation (ENSO) distribution of habitat suitability for BUM and BLM in the EPO predicted by yearly MaxEnt simulations. El Niño and La Niña extremes according to Oceanic Niño Index (ONI) values between 1997-2010. Color scale represents the probability of BUM and BLM presence (a,d) Niño Neutral Fall 2003, (b,e) El Niño Fall 1997, (c,f) La Niña Fall 2010. 

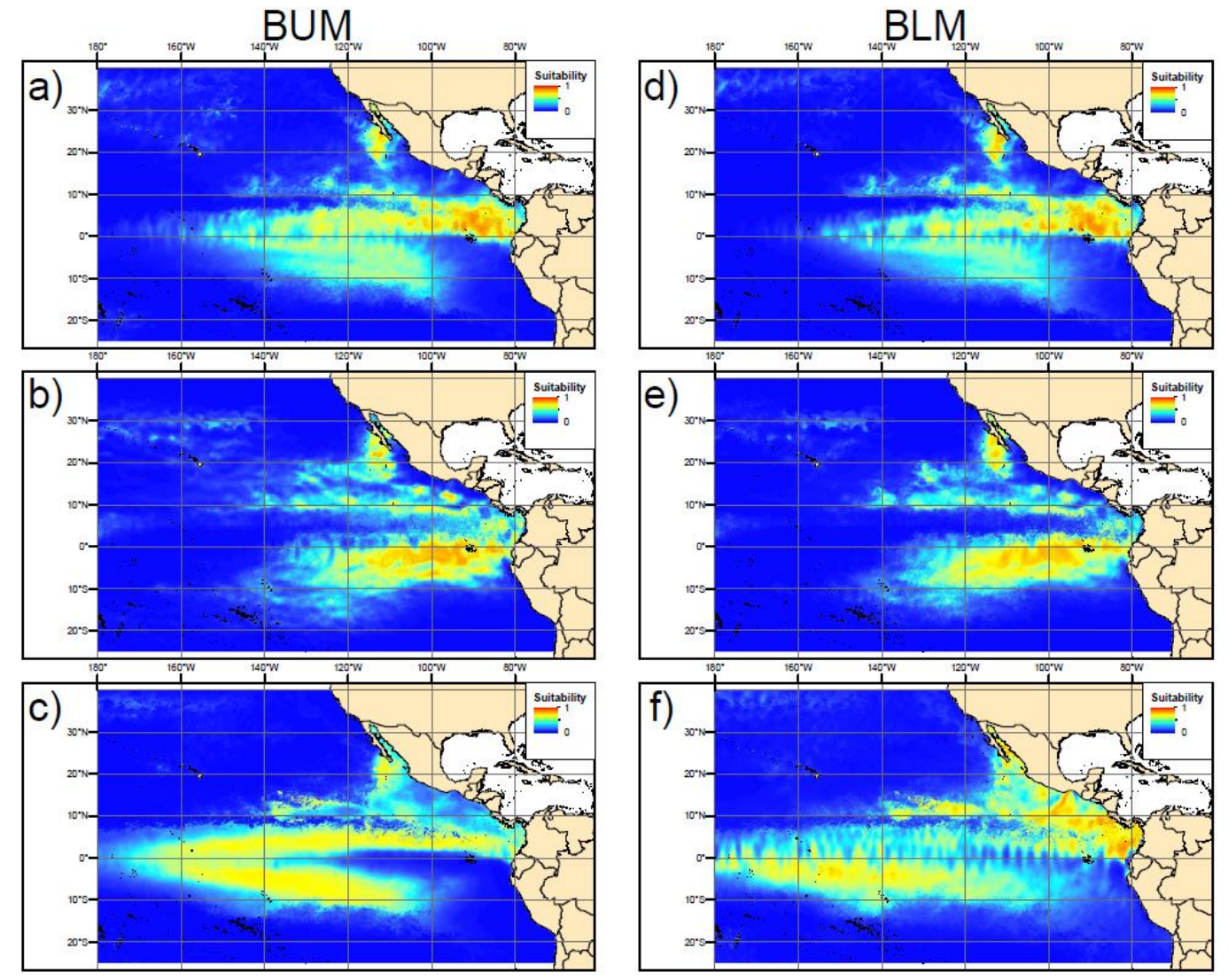
Figure 2.8 Relationship between Niño strength (based on ONI value) and BUM (top panels) and BLM (bottom panels) CSH longitude (left panels) and latitude (right panels). Colors of points and lines define season and shaded areas are 95\% upper and lower confidence levels. 

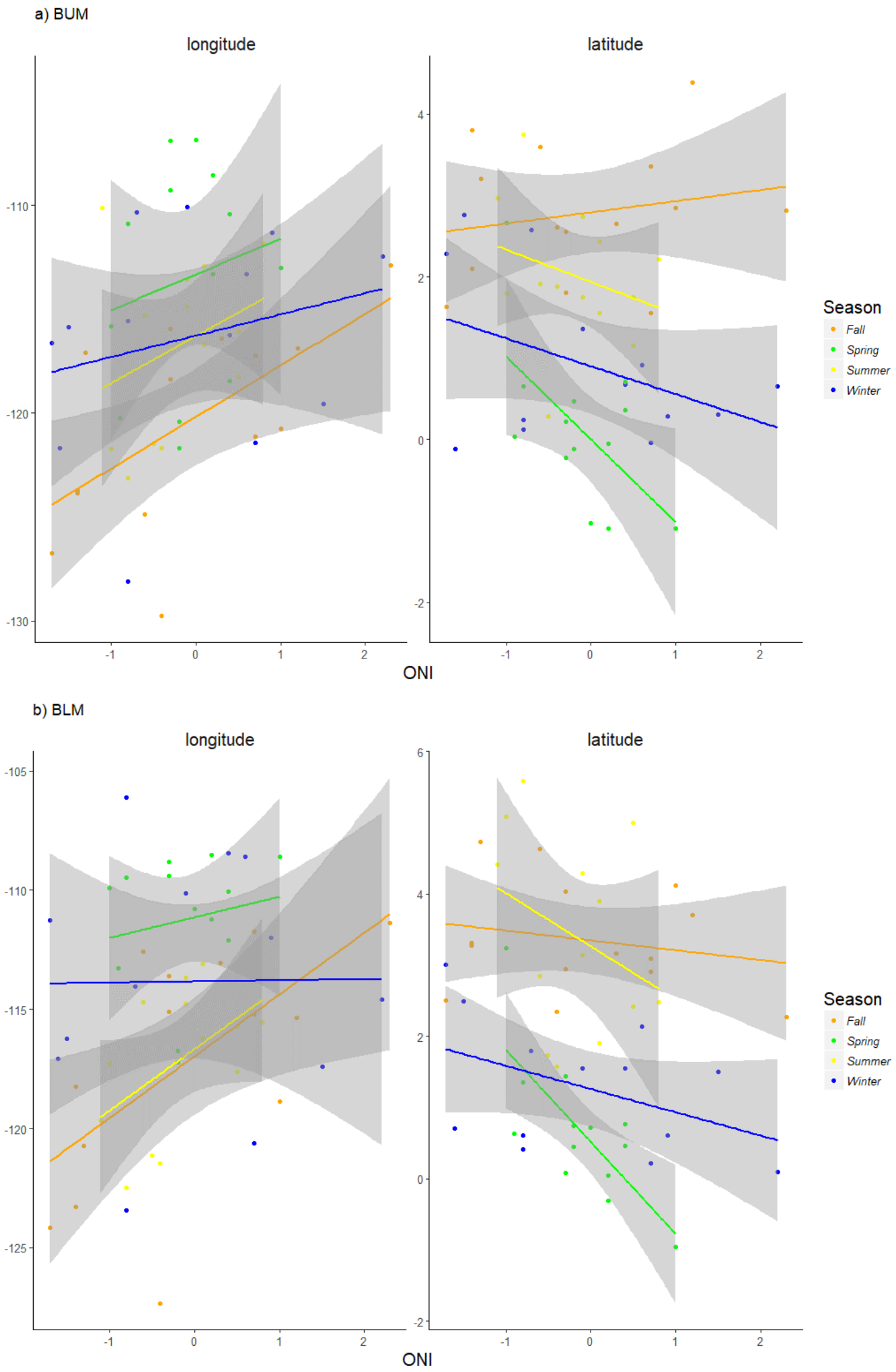


\section{References}

Acosta-Pachón, T. A., R. O. Martínez-Rincón, and M. G. Hinton. 2017. Habitat preferences of striped marlin (Kajikia audax) in the eastern Pacific Ocean. Fisheries Oceanography 26:615-624.

Amador, J. A., E. J. Alfaro, O. G. Lizano, and V. O. Magaña. 2006. Atmospheric forcing of the eastern tropical Pacific: A review. Progress in Oceanography 69:101-142.

Ballance, L. T., R. L. Pitman, and P. C. Fiedler. 2006. Oceanographic influences on seabirds and cetaceans of the eastern tropical Pacific: a review. Progress in Oceanography 69:360-390.

Baum, J. K., and B. Worm. 2009. Cascading top-down effects of changing oceanic predator abundances. Journal of Animal Ecology 78:699-714.

Block, B., D. Booth, and F. Carey. 1992. Depth and temperature of the blue marlin, Makaira nigricans, observed by acoustic telemetry. Marine Biology 114:175-183.

Boyce, D. G., D. P. Tittensor, and B. Worm. 2008. Effects of temperature on global patterns of tuna and billfish richness. Marine Ecology Progress Series 355:267-276.

Brill, R. W., and M. E. Lutcavage. 2001. Understanding environmental influences on movements and depth distributions of tunas and billfishes can significantly improve population assessments. Pages 179-198 in American Fisheries Society Symposium. American Fisheries Society.

Bui, R., R. N. Buliung, and T. K. Remmel. 2012. A collection of functions for estimating centrographic statistics and computational geometries for spatial point patterns. $\mathrm{R}$ package version $3.2 \mathrm{https} / / / C R A N . R-$ project.org/package=aspace.

Cai, W., S. Borlace, M. Lengaigne, P. Van Rensch, M. Collins, G. Vecchi, A. Timmermann, A. Santoso, M. J. McPhaden, and L. Wu. 2014. Increasing frequency of extreme El Niño events due to greenhouse warming. Nature Climate Change 4:111.

Campbell, R. A., J. G. Pepperell, and T. L. Davis. 2003. Use of charter boat data to infer the annual availability of black marlin, Makaira indica, to the recreational fishery off Cairns, Australia. Marine and Freshwater Research 54:447-457. 
Carlisle, A. B., R. E. Kochevar, M. C. Arostegui, J. E. Ganong, M. Castleton, J. Schratwieser, and B. A. Block. 2017. Influence of temperature and oxygen on the distribution of blue marlin (Makaira nigricans) in the Central Pacific. Fisheries Oceanography 26:34-48.

Chiang, W.-C., M. K. Musyl, C.-L. Sun, G. DiNardo, H.-M. Hung, H.-C. Lin, S.C. Chen, S.-Z. Yeh, W.-Y. Chen, and C.-L. Kuo. 2015. Seasonal movements and diving behaviour of black marlin (Istiompax indica) in the northwestern Pacific Ocean. Fisheries Research 166:92-102.

Coleman, F. C., W. F. Figueira, J. S. Ueland, and L. B. Crowder. 2004. The impact of United States recreational fisheries on marine fish populations. Science 305:1958-1960.

Domeier, M. L., and P. Speare. 2012. Dispersal of adult black marlin (Istiompax indica) from a Great Barrier Reef spawning aggregation. PloS one 7:e31629.

Donohoe, A., J. Marshall, D. Ferreira, and D. Mcgee. 2013. The relationship between ITCZ location and cross-equatorial atmospheric heat transport: From the seasonal cycle to the Last Glacial Maximum. Journal of Climate 26:3597-3618.

Ehrhardt, N. M., and M. D. Fitchett. 2006. On the seasonal dynamic characteristics of the sailfish, Istiophorus platypterus, in the eastern Pacific off Central America. Bulletin of Marine Science 79:589-606.

Elith, J., C. H. Graham, R. P. Anderson, M. Dudík, S. Ferrier, A. Guisan, R. J. Hijmans, F. Huettmann, J. R. Leathwick, and A. Lehmann. 2006. Novel methods improve prediction of species' distributions from occurrence data. Ecography:129-151.

Elith, J., S. J. Phillips, T. Hastie, M. Dudík, Y. E. Chee, and C. J. Yates. 2011. A statistical explanation of MaxEnt for ecologists. Diversity and distributions 17:43-57.

Fernández-Álamo, M. A., and J. Färber-Lorda. 2006. Zooplankton and the oceanography of the eastern tropical Pacific: a review. Progress in Oceanography 69:318-359.

Fritsches, K. A., N. J. Marshall, and E. J. Warrant. 2003. Retinal specializations in the blue marlin: eyes designed for sensitivity to low light levels. Marine and Freshwater Research 54:333-341. 
Garcia, S. M., and K. L. Cochrane. 2005. Ecosystem approach to fisheries: a review of implementation guidelines. ICES Journal of Marine Science 62:311-318.

Godø, O. R., A. Samuelsen, G. J. Macaulay, R. Patel, S. S. Hjøllo, J. Horne, S. Kaartvedt, and J. A. Johannessen. 2012. Mesoscale eddies are oases for higher trophic marine life. PloS one 7:e30161.

Goodyear, C. 1999. An analysis of the possible utility of time-area closures to minimize billfish bycatch by US pelagic longlines. Fishery BulletinNational Oceanic and Atmospheric Administratio 97:243-255.

Goodyear, C. P., J. Luo, E. D. Prince, J. P. Hoolihan, D. Snodgrass, E. S. Orbesen, and J. E. Serafy. 2008. Vertical habitat use of Atlantic blue marlin Makaira nigricans: interaction with pelagic longline gear. Marine Ecology Progress Series 365:233-245.

Graves, J. E., B. E. Luckhurst, and E. D. Prince. 2002. An evaluation of pop-up satellite tags for estimating postrelease survival of blue marlin (Makaira nigricans) from a recreational fishery. Fishery Bulletin 100:134-142.

Gunn, J. S., T. A. Patterson, and J. G. Pepperell. 2003. Short-term movement and behaviour of black marlin Makaira indica in the Coral Sea as determined through a pop-up satellite archival tagging experiment. Marine and Freshwater Research 54:515-525.

Hill, N. J., A. J. Tobin, A. E. Reside, J. G. Pepperell, and T. C. Bridge. 2016. Dynamic habitat suitability modelling reveals rapid poleward distribution shift in a mobile apex predator. Global change biology 22:1086-1096.

Hinton, M. G. 2001. Status of blue marlin in the Pacific Ocean. Inter-Amer. Trop. Tuna Comm., Stock Assess. Rep 1:284-319.

Hinton, M. G. 2015. Oceanographic conditions in the EPO and their effect on tuna fisheries.in Inter-Amer. Trop. Tuna Comm. 6th Scient. Adv. Com. Meeting. SAC-06 INF-C.

Hobday, A. J., and K. Evans. 2013. Detecting climate impacts with oceanic fish and fisheries data. Climatic Change 119:49-62.

Hobday, A. J., J. R. Hartog, C. M. Spillman, and O. Alves. 2011. Seasonal forecasting of tuna habitat for dynamic spatial management. Canadian Journal of Fisheries and Aquatic Sciences 68:898-911. 
Hobday, A. J., S. M. Maxwell, J. Forgie, and J. McDonald. 2013. Dynamic ocean management: integrating scientific and technological capacity with law, policy, and management. Stan. Envtl. LJ 33:125.

Holland, K., R. Brill, and R. K. Chang. 1990. Horizontal and vertical movements of Pacific blue marlin captured and released using sportfishing gear. Fishery Bulletin 88:397-402.

Hoolihan, J. P., J. Luo, D. Snodgrass, E. S. Orbesen, A. M. Barse, and E. D. Prince. 2015. Vertical and horizontal habitat use by white marlin Kajikia albida (Poey, 1860) in the western North Atlantic Ocean. ICES Journal of Marine Science 72:2364-2373.

Howard, J. K., and S. Ueyanagi. 1965. Distribution and relative abundance of billfishes (Istiophoridae) of the Pacific Ocean.

Huyer, A. 1983. Coastal upwelling in the California Current system. Progress in Oceanography 12:259-284.

Hyrenbach, K. D., C. Keiper, S. Allen, D. Ainley, and D. Anderson. 2006. Use of marine sanctuaries by far-ranging predators: commuting flights to the California Current System by breeding Hawaiian albatrosses. Fisheries Oceanography 15:95-103.

Jackson, J. B. C., M. X. Kirby, W. H. Berger, K. A. Bjorndal, L. W. Botsford, B. J. Bourque, R. H. Bradbury, R. Cooke, J. Erlandson, J. A. Estes, T. P. Hughes, S. Kidwell, C. B. Lange, H. S. Lenihan, J. M. Pandolfi, C. H. Peterson, R. S. Steneck, M. J. Tegner, and R. R. Warner. 2001. Historical overfishing and the recent collapse of coastal ecosystems. Science 293:629-638.

Jensen, O. P., S. Ortega-Garcia, S. J. D. Martell, R. N. M. Ahrens, M. L. Domeier, C. J. Walters, and J. F. Kitchell. 2010. Local management of a "highly migratory species": The effects of long-line closures and recreational catch-and-release for Baja California striped marlin fisheries. Progress in Oceanography 86:176-186.

Kessler, W. S. 2006. The circulation of the eastern tropical Pacific: A review. Progress in Oceanography 69:181-217.

Kitchell, J. F., S. J. D. Martell, C. J. Walters, O. P. Jensen, I. C. Kaplan, J. Watters, T. E. Essington, and C. H. Boggs. 2006. Billfishes in an ecosystem context. Bulletin of Marine Science 79:669-682. 
Kleiber, P., M. G. Hinton, and Y. Uozumi. 2003. Stock assessment of blue marlin (Makaira nigricans) in the Pacific using MULTIFAN-CL. Marine and Freshwater Research 54:349-360.

Kleisner, K. M., M. J. Fogarty, S. McGee, J. A. Hare, S. Moret, C. T. Perretti, and V. S. Saba. 2017. Marine species distribution shifts on the US Northeast Continental Shelf under continued ocean warming. Progress in Oceanography 153:24-36.

Kobayashi, D. R., J. J. Polovina, D. M. Parker, N. Kamezaki, I.-J. Cheng, I. Uchida, P. H. Dutton, and G. H. Balazs. 2008. Pelagic habitat characterization of loggerhead sea turtles, Caretta caretta, in the North Pacific Ocean (1997-2006): insights from satellite tag tracking and remotely sensed data. Journal of Experimental Marine Biology and Ecology 356:96-114.

Lewison, R., A. J. Hobday, S. Maxwell, E. Hazen, J. R. Hartog, D. C. Dunn, D. Briscoe, S. Fossette, C. E. O'keefe, and M. Barnes. 2015. Dynamic ocean management: identifying the critical ingredients of dynamic approaches to ocean resource management. BioScience 65:486-498.

Maxwell, S. M., E. L. Hazen, R. L. Lewison, D. C. Dunn, H. Bailey, S. J. Bograd, D. K. Briscoe, S. Fossette, A. J. Hobday, and M. Bennett. 2015. Dynamic ocean management: Defining and conceptualizing real-time management of the ocean. Marine Policy 58:42-50.

Maxwell, S. M., E. L. Hazen, L. E. Morgan, H. Bailey, and R. Lewison. 2012. Finding balance in fisheries management. Science 336:413-413.

Molony, B. 2005. Summary of the biology, ecology and stock status of billfishes in the WCPFC, with a review of major variables influencing longline fishery performance.in 1st Meeting of the Scientific Committee of the Western and Central Pacific Fisheries Commission (WCPFC-SC1), New Caledonia: Noumea, 8-19 August 2005.

Morato, T., S. D. Hoyle, V. Allain, and S. J. Nicol. 2010. Seamounts are hotspots of pelagic biodiversity in the open ocean. Proceedings of the National Academy of Sciences 107:9707-9711.

Myers, R. A., and B. Worm. 2003. Rapid worldwide depletion of predatory fish communities. Nature 423:280.

Nakamura, I. 1985. Billfishes of the world: an annotated and illustrated catalogue of marlins, sailfishes, spearfishes, and swordfishes known to date. United Nations Development Programme, Food and Agriculture Organization of the United Nations. 
Olson, D. B., G. L. Hitchcock, A. J. Mariano, C. J. Ashjian, G. Peng, R. W. Nero, and G. P. Podestá. 1994. Life on the edge: marine life and fronts. Oceanography 7:52-60.

Ortega-García, S., E. Camacho-Bareño, and R. O. Martínez-Rincón. 2015. Effects of environmental factors on the spatio-temporal distribution of striped marlin catch rates off Cabo San Lucas, Baja California Sur, Mexico. Fisheries Research 166:47-58.

Pearce, J., S. Ferrier, and D. Scotts. 2001. An evaluation of the predictive performance of distributional models for flora and fauna in north-east New South Wales. Journal of Environmental Management 62:171-184.

Pennington, J. T., K. L. Mahoney, V. S. Kuwahara, D. D. Kolber, R. Calienes, and F. P. Chavez. 2006. Primary production in the eastern tropical Pacific: a review. Progress in Oceanography 69:285-317.

Pepperell, J. 2011. NSW DPI Game Fish Tagging Program Report 2010-2011. Pepperell Research:29.

Pershing, A. J., M. A. Alexander, C. M. Hernandez, L. A. Kerr, A. Le Bris, K. E. Mills, J. A. Nye, N. R. Record, H. A. Scannell, and J. D. Scott. 2015. Slow adaptation in the face of rapid warming leads to collapse of the Gulf of Maine cod fishery. Science 350:809-812.

Phillips, S. J., R. P. Anderson, and R. E. Schapire. 2006. Maximum entropy modeling of species geographic distributions. Ecological Modelling 190:231-259.

Pinsky, M. L., B. Worm, M. J. Fogarty, J. L. Sarmiento, and S. A. Levin. 2013. Marine taxa track local climate velocities. Science 341:1239-1242.

Prince, E. D., and C. P. Goodyear. 2006. Hypoxia-based habitat compression of tropical pelagic fishes. Fisheries Oceanography 15:451-464.

Reside, A. E., I. Watson, J. VanDerWal, and A. S. Kutt. 2011. Incorporating lowresolution historic species location data decreases performance of distribution models. Ecological Modelling 222:3444-3448.

Scales, K. L., E. L. Hazen, S. M. Maxwell, H. Dewar, S. Kohin, M. G. Jacox, C. A. Edwards, D. K. Briscoe, L. B. Crowder, and R. L. Lewison. 2017. Fit to predict? Eco-informatics for predicting the catchability of a pelagic fish in near real time. Ecological Applications 27:2313-2329. 
Seki, M. P., R. Lumpkin, and P. Flament. 2002. Hawaii cyclonic eddies and blue marlin catches: the case study of the 1995 Hawaiian International Billfish Tournament. Journal of Oceanography 58:739-745.

Shimose, T., H. Shono, K. Yokawa, H. Saito, and K. Tachihara. 2006. Food and feeding habits of blue marlin, Makaira nigricans, around Yonaguni Island, southwestern Japan. Bulletin of Marine Science 79:761-775.

Shimose, T., K. Yokawa, and H. Saito. 2010. Habitat and food partitioning of billfishes (Xiphioidei). Journal of fish biology 76:2418-2433.

Shimose, T., K. Yokawa, H. Saito, and K. Tachihara. 2008. Seasonal occurrence and feeding habits of black marlin, Istiompax indica, around Yonaguni Island, southwestern Japan. Ichthyological Research 55:90-94.

Shimose, T., K. Yokawa, H. Saito, and K. Tachihara. 2012. Sexual difference in the migration pattern of blue marlin, Makaira nigricans, related to spawning and feeding activities in the western and central North Pacific Ocean. Bulletin of Marine Science 88:231-249.

Sibert, J., J. Hampton, P. Kleiber, and M. Maunder. 2006. Biomass, size, and trophic status of top predators in the Pacific Ocean. Science 314:17731776.

Sinclair, M., R. Arnason, J. Csirke, Z. Karnicki, J. Sigurjonsson, H. R. Skjoldal, and G. Valdimarsson. 2002. Responsible fisheries in the marine ecosystem. Fisheries Research 58:255-265.

Skillman, R. A. 1988. Status of Pacific billfish stocks. Pages 179-195 in Planning the Future of Billfishes: Research and Management in the 90s and Beyond. Proceedings of the Second International Billfish Symposium, Kailua-Kona, Hawaii.

Squire Jr, J. L., and D. V. Nielsen. 1983. Results of a tagging program to determine migration rates and patterns for black marlin, Makaira indica, in the southwest Pacific Ocean. NOAA technical report NMFS SSRFUnited States. National Marine Fisheries Service (USA). no. 772.

Stramma, L., E. D. Prince, S. Schmidtko, J. Luo, J. P. Hoolihan, M. Visbeck, D. W. Wallace, P. Brandt, and A. Körtzinger. 2012. Expansion of oxygen minimum zones may reduce available habitat for tropical pelagic fishes. Nature Climate Change 2:33. 
Su, N. J., C.-L. Sun, A. E. Punt, S.-Z. Yeh, and G. DiNardo. 2011. Modelling the impacts of environmental variation on the distribution of blue marlin, Makaira nigricans, in the Pacific Ocean. ICES Journal of Marine Science 68:1072-1080.

Su, N. J., C. L. Sun, A. E. Punt, and S. Z. Yeh. 2008. Environmental and spatial effects on the distribution of blue marlin (Makaira nigricans) as inferred from data for longline fisheries in the Pacific Ocean. Fisheries Oceanography 17:432-445.

Timmermann, A., J. Oberhuber, A. Bacher, M. Esch, M. Latif, and E. Roeckner. 1999. Increased El Niño frequency in a climate model forced by future greenhouse warming. Nature 398:694.

Whitlock, M. C., and D. Schluter. 2009. The analysis of biological data.

Willett, C., R. Leben, and M. Lavin. 2006. Eddies and mesoscale processes in the eastern tropical Pacific: a review. Progress in Oceanography 69:218-238.

Woodworth, P. A., G. S. Schorr, R. W. Baird, D. L. Webster, D. J. McSweeney, M. B. Hanson, R. D. Andrews, and J. J. Polovina. 2012. Eddies as offshore foraging grounds for melon-headed whales (Peponocephala electra). Marine Mammal Science 28:638-647.

Worm, B., R. Hilborn, J. K. Baum, T. A. Branch, J. S. Collie, C. Costello, M. J. Fogarty, E. A. Fulton, J. A. Hutchings, and S. Jennings. 2009. Rebuilding global fisheries. Science 325:578-585. 


\section{CHAPTER 3: CONCLUSION}

Determining spatiotemporal distributions, habitat uses, and environmental preferences is paramount for understanding how marine organisms respond to environmental or anthropogenic influences and is needed for generating effective management strategies. The relationships between environmental factors and suitable habitat derived from this study can be utilized to forecast the seasonal and ENSO spatial distributions of BUM and BLM if oceans continue to warm as predicted under climate change scenarios. Global SST has increased at a rate of $0.01^{\circ} \mathrm{C}$ over the past decade, which has led to distribution shifts of many fish populations (Pinsky et al. 2013, Pershing et al. 2015, Kleisner et al. 2017). Because BUM and BLM spatial distribution is driven by high CHLA and warm SST waters, the suitable habitat of these fish may potentially shift more productive and cooler coastal waters of the EPO as ocean warming continues. Furthermore, BUM and BLM suitable habitat may shift shoreward if El Niño become more common as a result of climate change (Timmermann et al. 1999, Cai et al. 2014). Given that recreational fishing, which is concentrated close to shore, is a significant source of mortality for marlin, shoreward shifts in distribution could increase mortality in the future. Further study on the degree to which recreational fishing may affect marlin stock viability in a changing climate is necessary to ensure effective management of these fishes.

Previous studies suggested that time-area closures are the best approach to manage the fisheries and reduce bycatch of billfish (Goodyear 1999). However, static approaches, such as time-area closures, may be less effective in managing 
highly mobile organisms, which respond rapidly to shifting ocean conditions (Hyrenbach et al. 2006). A dynamic ocean management framework, described as management changing rapidly in space and time in response to the shifting nature of the ocean and its users based on the integration of near real-time biological, oceanographic, social and/or economic data may be more suited in managing these species (Maxwell et al. 2012, Hobday et al. 2013, Lewison et al. 2015, Maxwell et al. 2015). Because the oceans are in constant flux, the ability to accurately describe a species habitat in near real-time would greatly increase the efficiency of management by maintaining target catch within quota limits, reducing bycatch, and most effectively assessing the amount of area managed to be closed (Lewison et al. 2015, Maxwell et al. 2015). For example, if seasonal shifts of the suitable habits of BUM and BLM can be determined accurately and provided to the regulatory or resource management agencies, specific strategies can be formulated accordingly to manage these species in different seasons throughout the year.

Ecological information can be difficult to determine for highly migratory species, due to their naturally low population densities and patchy distributions (Hill et al. 2016), which may result in low spatial and temporal resolution data (Hobday and Even, 2013). While studies utilizing data from tags (Squire Jr and Nielsen 1983, Holland et al. 1990, Prince and Goodyear 2006, Chiang et al. 2015, Hoolihan et al. 2015, Carlisle et al. 2017) and industrialized fisheries, such as longline fisheries (Su et al. 2008, Shimose et al. 2010, Su et al. 2011), provided useful information on species movements and habitat use, tagging studies can be expensive and spatiotemporally limited (Hobday and Evans 2013) and industrial 
fisheries do not cover all ecologically-important species. Here, we used fine scale BUM and BLM bycatch data from the EPO tuna purse-seine fishery to demonstrate the potential contribution of SDMs of highly migratory species to fisheries management. Future work should compare our SDM results, built upon remotely sensed datasets, with those built upon near real-time data assimilation ocean circulation models, as they avoid limitations of satellite remotely sensed data (e.g. cloud cover, variable resolution) and can potentially lead to superior predictive performance (Scales et al. 2017). Given the success of our models for two highly migratory species, methods presented here can be applied to other mobile marine species that may be affected by a changing climate. 


\section{References}

Carlisle, A. B., R. E. Kochevar, M. C. Arostegui, J. E. Ganong, M. Castleton, J. Schratwieser, and B. A. Block. 2017. Influence of temperature and oxygen on the distribution of blue marlin (Makaira nigricans) in the Central Pacific. Fisheries Oceanography 26:34-48.

Goodyear, C. 1999. An analysis of the possible utility of time-area closures to minimize billfish bycatch by US pelagic longlines. Fishery BulletinNational Oceanic and Atmospheric Administratio 97:243-255.

Hill, N. J., A. J. Tobin, A. E. Reside, J. G. Pepperell, and T. C. Bridge. 2016. Dynamic habitat suitability modelling reveals rapid poleward distribution shift in a mobile apex predator. Global change biology 22:1086-1096.

Hobday, A. J., and K. Evans. 2013. Detecting climate impacts with oceanic fish and fisheries data. Climatic Change 119:49-62.

Hobday, A. J., S. M. Maxwell, J. Forgie, and J. McDonald. 2013. Dynamic ocean management: integrating scientific and technological capacity with law, policy, and management. Stan. Envtl. LJ 33:125.

Holland, K., R. Brill, and R. K. Chang. 1990. Horizontal and vertical movements of Pacific blue marlin captured and released using sportfishing gear. Fishery Bulletin 88:397-402.

Hoolihan, J. P., J. Luo, D. Snodgrass, E. S. Orbesen, A. M. Barse, and E. D. Prince. 2015. Vertical and horizontal habitat use by white marlin Kajikia albida (Poey, 1860) in the western North Atlantic Ocean. ICES Journal of Marine Science 72:2364-2373.

Hyrenbach, K. D., C. Keiper, S. Allen, D. Ainley, and D. Anderson. 2006. Use of marine sanctuaries by far-ranging predators: commuting flights to the California Current System by breeding Hawaiian albatrosses. Fisheries Oceanography 15:95-103.

Kleisner, K. M., M. J. Fogarty, S. McGee, J. A. Hare, S. Moret, C. T. Perretti, and V. S. Saba. 2017. Marine species distribution shifts on the US Northeast Continental Shelf under continued ocean warming. Progress in Oceanography 153:24-36.

Lewison, R., A. J. Hobday, S. Maxwell, E. Hazen, J. R. Hartog, D. C. Dunn, D. Briscoe, S. Fossette, C. E. O'keefe, and M. Barnes. 2015. Dynamic ocean management: identifying the critical ingredients of dynamic approaches to ocean resource management. BioScience 65:486-498. 
Maxwell, S. M., E. L. Hazen, R. L. Lewison, D. C. Dunn, H. Bailey, S. J. Bograd, D. K. Briscoe, S. Fossette, A. J. Hobday, and M. Bennett. 2015. Dynamic ocean management: Defining and conceptualizing real-time management of the ocean. Marine Policy 58:42-50.

Maxwell, S. M., E. L. Hazen, L. E. Morgan, H. Bailey, and R. Lewison. 2012. Finding balance in fisheries management. Science 336:413-413.

Pershing, A. J., M. A. Alexander, C. M. Hernandez, L. A. Kerr, A. Le Bris, K. E. Mills, J. A. Nye, N. R. Record, H. A. Scannell, and J. D. Scott. 2015. Slow adaptation in the face of rapid warming leads to collapse of the Gulf of Maine cod fishery. Science 350:809-812.

Pinsky, M. L., B. Worm, M. J. Fogarty, J. L. Sarmiento, and S. A. Levin. 2013. Marine taxa track local climate velocities. Science 341:1239-1242.

Prince, E. D., and C. P. Goodyear. 2006. Hypoxia-based habitat compression of tropical pelagic fishes. Fisheries Oceanography 15:451-464.

Scales, K. L., E. L. Hazen, S. M. Maxwell, H. Dewar, S. Kohin, M. G. Jacox, C. A. Edwards, D. K. Briscoe, L. B. Crowder, and R. L. Lewison. 2017. Fit to predict? Eco-informatics for predicting the catchability of a pelagic fish in near real time. Ecological Applications 27:2313-2329.

Shimose, T., K. Yokawa, and H. Saito. 2010. Habitat and food partitioning of billfishes (Xiphioidei). Journal of fish biology 76:2418-2433.

Squire Jr, J. L., and D. V. Nielsen. 1983. Results of a tagging program to determine migration rates and patterns for black marlin, Makaira indica, in the southwest Pacific Ocean. NOAA technical report NMFS SSRFUnited States. National Marine Fisheries Service (USA). no. 772.

Su, N. J., C.-L. Sun, A. E. Punt, S.-Z. Yeh, and G. DiNardo. 2011. Modelling the impacts of environmental variation on the distribution of blue marlin, Makaira nigricans, in the Pacific Ocean. ICES Journal of Marine Science 68:1072-1080.

Su, N. J., C. L. Sun, A. E. Punt, and S. Z. Yeh. 2008. Environmental and spatial effects on the distribution of blue marlin (Makaira nigricans) as inferred from data for longline fisheries in the Pacific Ocean. Fisheries Oceanography 17:432-445.

Timmermann, A., J. Oberhuber, A. Bacher, M. Esch, M. Latif, and E. Roeckner. 1999. Increased El Niño frequency in a climate model forced by future greenhouse warming. Nature 398:694. 